\title{
Lipid Transport between the Endoplasmic Reticulum and Mitochondria
}

\author{
Vid V. Flis and Günther Daum \\ Institute of Biochemistry, Graz University of Technology, A-8010 Graz, Austria \\ Correspondence: guenther.daum@tugraz.at
}

Mitochondria are partially autonomous organelles that depend on the import of certain proteins and lipids to maintain cell survival and membrane formation. Although phosphatidylglycerol, cardiolipin, and phosphatidylethanolamine are synthesized by mitochondrial enzymes, phosphatidylcholine, phosphatidylinositol, phosphatidylserine, and sterols need to be imported from other organelles. The origin of most lipids imported into mitochondria is the endoplasmic reticulum, which requires interaction of these two subcellular compartments. Recently, protein complexes that are involved in membrane contact between endoplasmic reticulum and mitochondria were identified, but their role in lipid transport is still unclear. In the present review, we describe components involved in lipid translocation between the endoplasmic reticulum and mitochondria and discuss functional as well as regulatory aspects that are important for lipid homeostasis.

B iological membranes are major structural components of all cell types. They protect the cell from external influences, organize the interior in distinct compartments and allow balanced flux of components. Besides their specific proteome, organelles exhibit unique lipid compositions, which influence their shape, physical properties, and function. Major lipid classes found in biological membranes are phospholipids, sterols, and sphingolipids.

The major "lipid factory" within the cell is the endoplasmic reticulum (ER). It is able to synthesize the bulk of structural phospholipids, sterols, and storage lipids such as triacylglycerols and steryl esters (van Meer et al. 2008). Furthermore, initial steps of ceramide synthesis occur in the ER providing precursors for the formation of complex sphingolipids in other organelles (Futerman 2006). Besides the export of ceramides, the ER supplies a large portion of lipids to other organelles, which cannot produce their own lipids or have a limited capacity to do so. Organelle interaction and transport of lipids require specific carrier proteins, membrane contact sites, tethering complexes, and/ or vesicle flux. These processes are highly important for the maintenance of cell structure and survival but are still a matter of dispute. Most prominent organelle interaction partners are the ER and mitochondria. A subfraction of the ER named mitochondria-associated membrane (MAM) (Vance 1990) was described to be involved in lipid translocation to mitochondria. MAM is part of the ER network, which was shown to be in contact or close proximity to the outer mitochondrial membrane (OMM).

Editors: Susan Ferro-Novick, Tom A. Rapoport, and Randy Schekman

Additional Perspectives on The Endoplasmic Reticulum available at www.cshperspectives.org

Copyright (C) 2013 Cold Spring Harbor Laboratory Press; all rights reserved; doi: 10.1101/cshperspect.a013235

Cite this article as Cold Spring Harb Perspect Biol 2013;5:a013235 
V.V. Flis and G. Daum

Contact sites between MAM and mitochondria were assumed to facilitate exchange of components between the two compartments. Interestingly, MAM harbor a number of lipid synthesizing enzymes (Gaigg et al. 1994). Recently, molecular components governing membrane contact between the two organelles were identified (Dolman et al. 2005; Csordás et al. 2006; de Brito and Scorrano 2008; Kornmann et al. 2009; Friedman et al. 2010; Lavieu et al. 2010), although the specific role of these components in lipid translocation is not yet clear.

\section{MAJOR PHOSPHOLIPID CLASSES OF MITOCHONDRIA}

Cardiolipin (CL) and/or phosphatidylglycerol (PG) are considered as mitochondria-specific phospholipids (Zinser et al. 1991). Both lipids are synthesized by mitochondria themselves (Davidson and Stanacev 1971). The importance of CL for ATP-production has been shown with different membrane types, e.g., bacteria, hydrogenosomes, and mitochondria (Mileykovskaya et al. 2005; Schlame 2008; Acehan et al. 2011). In mitochondria, the majority of CL is localized to the inner membrane (IMM) (Zinser et al. 1991), but substantial amounts were also detected in the OMM (Gebert et al. 2009). With its uncommon, dimeric structure (Fig. 1) CL together with phosphatidylethanolamine (PE) interacts with many mitochondrial proteins (Osman et al. 2011) and stabilizes their conformation (Joshi et al. 2012). Mutants lacking CL and PE biosynthesis are synthetic lethal in yeast and bacteria (Gohil et al. 2005). In bacteria, both lipids are organized in membrane clusters (Matsumoto et al. 2006). Specific interaction partners of CL are proteins of ATP production, mitochondrial transport systems (Bogdanov et al. 2008a; Schlame and Ren 2009), and proteins required for mitochondrial structure and fusion (Joshi et al. 2012).

Another prominent mitochondrial phospholipid is PE. Mitochondria are able to synthesize a large portion of PE by decarboxylation of phosphatidylserine (PS) (Vial et al. 1982; Trotter et al. 1993; Emoto et al. 1999; Birner et al. 2001; Nerlich et al. 2007). With its small hydrophilic head group and large hydrophobic tail, PE is a typical nonbilayer-forming phospholipid (see Fig. 1). This structure appears to be important for some peripheral and integral membrane proteins (van den Brink-van der Laan et al. 2004). Together with CL, PE plays a crucial role in maintaining mitochondrial morphology. Loss of both PE and CL is lethal probably due to defects in mitochondrial fusion (Joshi et al. 2012) and/ or protein destabilizing (Bogdanov et al. 2008b; Osman et al. 2009b). Lack of PE synthesized in the IMM cannot be fully compensated by $\mathrm{PE}$ imported from extramitochondrial sites (Birner et al. 2001; Bürgermeister et al. 2004; Joshi et al. 2012). However, PE derived from exogenous lyso-PE can restore both intra- and extramitochondrial PE deficiencies by remodeling processes (Riekhof and Voelker 2006). Noteworthy, mitochondria are the major supplier of PE to other organelles (Voelker 1984).

Mitochondrial enzymes of CL and PG synthesis, as well as the major PS decarboxylase, are synthesized on cytosolic ribosomes, imported into mitochondria, and assembled into the IMM (Minskoff and Greenberg 1997; Jiang et al. 2000; Nowicki et al. 2005; Nebauer et al. 2007; Choi et al. 2012). Only recently were we able to demonstrate experimentally the involvement of components of the mitochondrial TOM complex and of mitochondrial proteases in import and processing of the mitochondrial PS decarboxylase Psd1p from the yeast (Horvath et al. 2012).

Phosphatidylcholine (PC) has a big hydrophilic head group and a long hydrophobic tail (see Fig. 1). Its cylindrical shape makes it a perfect component of bilayer membranes and its role as a structural component is essential (van Meer et al. 2008). Specific functions of PC in mitochondria are not well defined. Similar to PC, specific functions of phosphatidylinositol (PI) in mitochondria are not known, but its essential role in total cellular metabolism makes it directly or indirectly indispensible for the maintenance of mitochondria. The bulkhead group of PI makes this phospholipid a specific membrane bilayer component.

Phosphatidylserine (PS) has also a cylindrical shape that allows integration into bilayer 

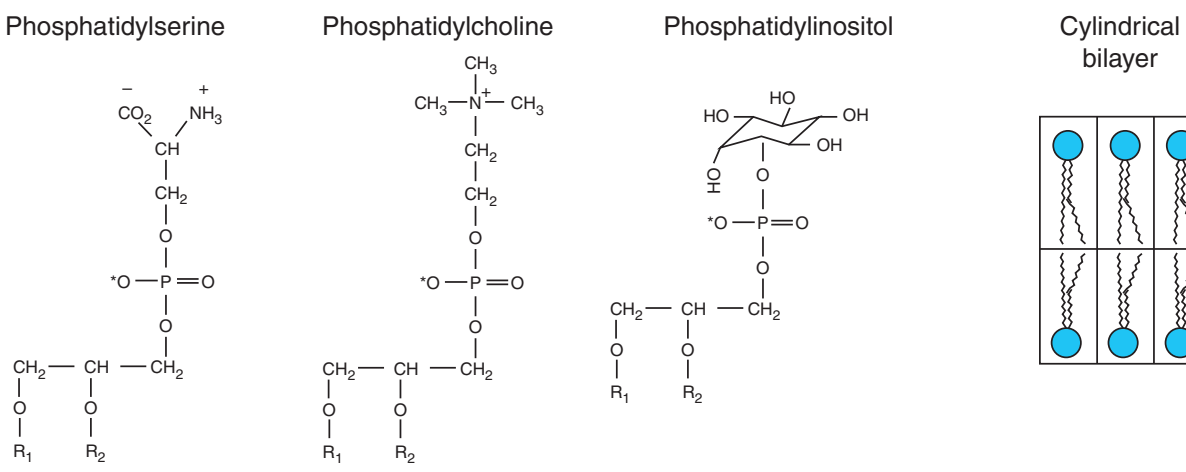

Cardiolipin

\section{Conical} nonbilayer

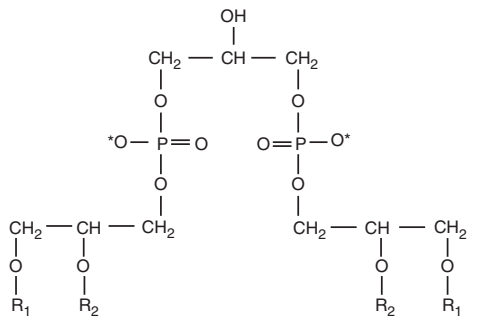

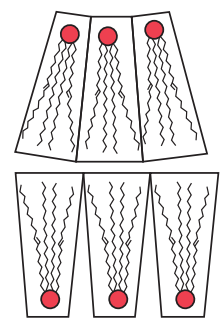

Phosphatidylethanolamine

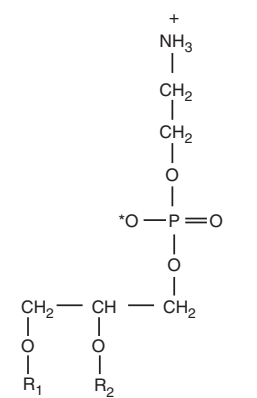

Conical nonbilayer

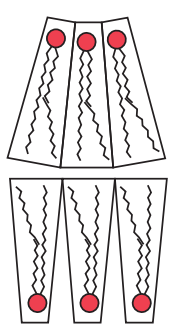

Figure 1. Major phospholipid classes of mitochondria. Chemical formulas and geometrical forms of the major mitochondrial phospholipids are shown. The shape-structure concept of lipids compares the area of the head group with the area of their acyl chains. If the cross-section area of the head group is similar to that of the acyl chains, lipids have an overall cylindrical shape and have a strong tendency of self-assembly into bilayer phases of biological membranes. A typical example for such geometry is PC. If the cross-section area of the head group is smaller than that of the acyl chains, lipids have a conical shape and form structures with negative curvature such as hexagonal phase. Examples of this type are PE and CL. While PC, PS, and PI exhibit cylindrical shape and self-organize into bilayers, PE and CL with their conical shape induce hexagonal phases and disturb bilayer arrangement.

membranes (see Fig. 1). Although PS is present in low concentrations in organelles of eukaryotic cells (Zinser and Daum 1995), it is important as a precursor for the two major phospholipids, PE and PC. Supply of PS to mitochondria is essential because in many cells the majority of $\mathrm{PE}$ is formed by decarboxylation of PS in mitochondria. The metabolic conversion of PS to PE upon import of PS into mitochondria provides a convenient biochemical method to study this import process (Voelker 1988, 1989b, 1991, 1992, 1993; Achleitner et al. 1995, 1999).

Typically, the lipid composition of mitochondria shows as major components $40 \%-$ $44 \%$ PC, $27 \%-34 \%$ PE, $1 \%-3 \%$ PS, 5\%$15 \% \mathrm{PI}$, and $13 \%-14 \% \mathrm{CL}$ depending on the cell type (Zinser and Daum 1995; Daum and
Vance 1997; van Meer 2008). OMM and IMM are strongly different with respect to their lipid equipment. Whereas the IMM is strongly enriched in proteins and contains only $20 \%$ lipids of total mass, the OMM is a lipid rich membrane (Zinser and Daum 1995; Dolis et al. 1996; Daum and Vance 1997). Accumulation of CL, PG, and also PE in the IMM appears to be related to functions mentioned above.

\section{SYNTHESIS OF AMINOGLYCEROPHOSPHOLIPIDS INVOLVES INTERACTION OF ORGANELLES}

The biosynthetic sequence of aminoglycerophospholipid formation starts with the synthesis of PS in the ER (Fig. 2). The highest 
V.V. Flis and G. Daum

A

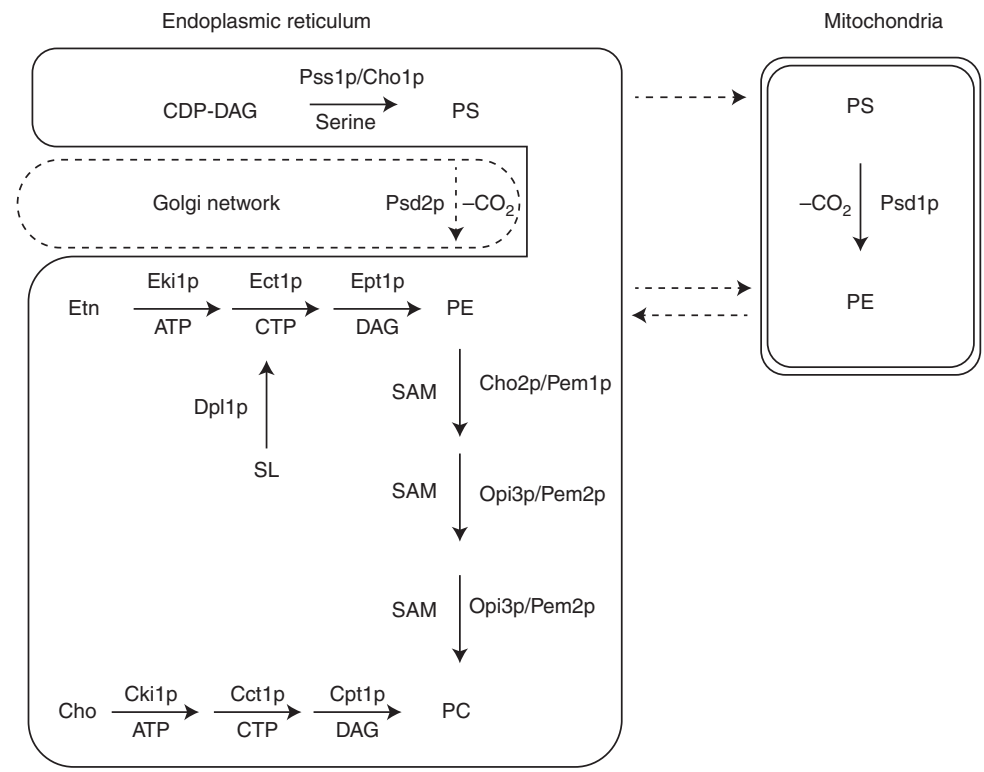

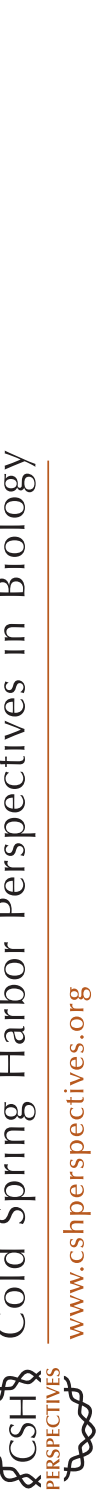

Endoplasmic reticulum

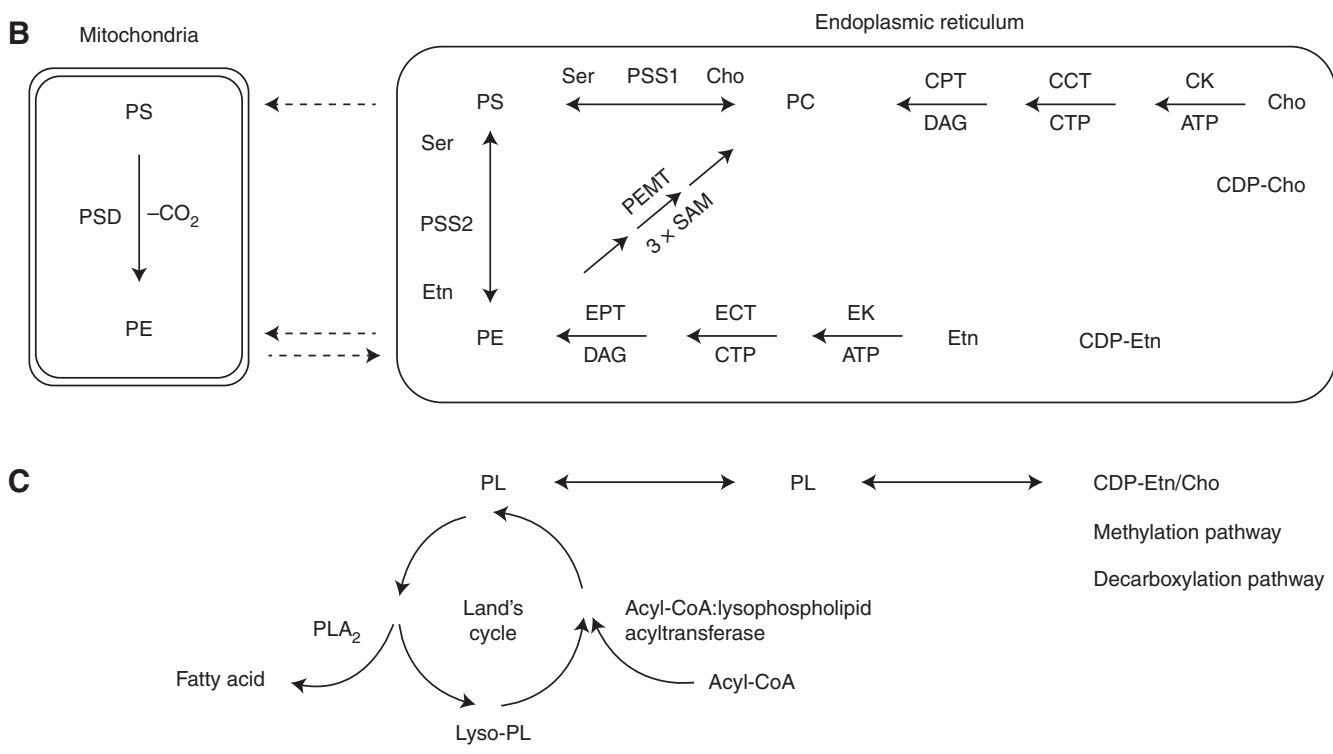

Figure 2. Biosynthetic pathways of aminoglycerophospholipids. (A) Biosynthesis of aminoglycerophospholipids in yeast. Formation of PS is accomplished in the ER and catalyzed in a CDP-DAG-dependent reaction by the PS synthase, Pss1p. Decarboxylation of PS yielding PE occurs in mitochondria (via Psd1p) and a Golgi/vacuolar compartment (via Psd2p). Three-step methylation of PE in the ER catalyzed by Cho2p/Pem1p and Opi3p/ Pem2p leads to formation of PC with S-adenosine methionine (SAM) as methyl donor. PC and PE can be formed also by the CDP-ethanolamine and CDP-choline branches of the so-called Kennedy pathway making use of exogenous or endogenous choline (Cho) and ethanolamine (Etn), respectively. SL, sphingolipids. (B) Aminoglycerophospholipid biosynthesis in mammalian cells. The major mechanism of PS production in mammals is base exchange with PC (PSS1) and PE (PSS2) as substrates. A major route of PE and PC production are the CDPethanolamine and CDP-choline pathways. In mammalian cells, $\mathrm{PE}$ can also be produced by decarboxylation of PS. In hepatocytes, a single methyltransferase catalyzes methylation of PE to PC. ( $C$ ) The Land's cycle describes a sequence of deacylation and reacylation. $\mathrm{PE}$ and $\mathrm{PC}$ are converted to lyso-PE and lyso-PC and vice versa. 
Lipid Transport between the ER and Mitochondria

concentration of PS synthesizing enzymes has been detected in the MAM (mitochondria-associated membrane) (Kuchler et al. 1986; Vance 1990). Interestingly, mammalian cells and yeast have different pathways to produce PS. In mammalian cells, two phosphatidylserine synthases (PSS-1 and PSS-2) produce PS by base exchange at the head group of PE or PC (Vance 2008) in a $\mathrm{Ca}^{2+}$-dependent reaction (Fig. 2B). This release of $\mathrm{Ca}^{2+}$ into the lumen of the ER is energy dependent. In yeast, formation of PS is catalyzed by the gene product of PSS1/CHO1 (Letts et al. 1983), which requires CDP-diacylglycerol (CDP-DAG) and serine (Nikawa and Yamashita 1981) as substrates and depends on $\mathrm{Mg}^{2+}$ or $\mathrm{Mn}^{2+}$ (Fig. 2A). Cellular energy is required for the formation of CDP-DAG. In plants, both pathways described above are active for PS production (Delhaize et al. 1999; Manoharan et al. 2000; Rontein et al. 2003). In all types of cells, PS synthesized in the ER is exported to other organelles, including mitochondria where it serves as a substrate for PE synthesis.

$\mathrm{PE}$ is the second most abundant lipid of eukaryotic cells. It can be synthesized by four different pathways: (i) the CDP-ethanolamine pathway (also named Kennedy pathway) (Kanfer and Kennedy 1964), (ii) decarboxylation of PS to PE, (iii) base exchange between different phospholipids, and (iv) acylation of lyso-PE (see Fig. 2). Yeast has two PS decarboxylases (PSD) with overlapping functions (Trotter et al. 1993). Psd1p is localized to mitochondria (Trotter et al. 1993), and Psd2p has been found in a Golgi/vacuolar compartment (Trotter and Voelker 1995). Psd1p is a component of the IMM/intermembrane space and produces the majority of total cellular and mitochondrial PE (Trotter et al. 1993; Birner et al. 2001).

Yeast can also produce PE through the CDPethanolamine branch of the Kennedy pathway (Kennedy and Weiss 1956). The CDP-ethanolamine pathway incorporates externally added or endogenous ethanolamine through stepwise phosphorylation, activation with CTP, and attachment to diacylglycerol (DAG). In the final step, phosphoethanolamine is transferred from CDP-ethanolamine to a DAG acceptor forming PE. However, PE synthesized through this pathway cannot fully complement for the mitochondrial requirement of $\mathrm{PE}$ in cells deleted of both PSD1 and PSD2 (Trotter and Voelker 1995). Ethanolamine phosphate, which is an intermediate in this biosynthetic sequence, can also be derived from sphingolipid degradation providing a link between sphingolipid and PE metabolism (Mao et al. 1997; Saba et al. 1997). Finally, yeast harbors enzymes that catalyze acylation of lyso-PE (Riekhof and Voelker 2006; Riekhof et al. 2007b; Deng et al. 2010). This type of reaction named Land's cycle includes deacylation/reacylation of phospholipids (Lands 1958) and appears to be important for remodeling processes. The reason for the existence of overlapping pathways is still a matter of dispute, although evidence for distinct pools of PE has been presented (Bürgermeister et al. 2004).

Mammalian cells have the capacity to synthesize their entire PE through the PSD pathway in mitochondria (Voelker and Frazier 1986), but in the presence of ethanolamine the CDPethanolamine pathway can fulfill most of the extramitochondrial requirements for this lipid (Vance 2008). The Land's cycle is important for remodeling phospholipids that have been formed by other pathways. As an example, formation of PE from lyso-PE can be accomplished by LPEAT2 (acyl-CoA:lysophosphatidylethanolamine acyltransferase 2) in the brain cells. Ethanolamine phospholipids are major constituents of the myelin sheath increasing the signal transmission speed along the axons (Cao et al. 2008). In plants, remodeling of PE to lyso-PE was reported to be involved in plant growth promotion and leaf senescence (Cowan 2009; Hong et al. 2009). In the parasites, Trypanosoma brucei and Plasmodium berghei, $\mathrm{PE}$ is exclusively produced through the CDP-ethanolamine branch of the Kennedy pathway (Serricchio and Bütikofer 2011).

PC is the most abundant phospholipid in eukaryotic cells (van Meer et al. 2008). Because mitochondria lack PC synthesizing enzymes, this phospholipid has to be imported from the ER. PC can be produced via three pathways: (i) the CDP-choline branch of the Kennedy pathway (Gibellini and Smith 2010), (ii) methylation 
V.V. Flis and G. Daum

of PE (Sundler and Akesson 1975; Li et al. 2005), and (iii) the Land's cycle, in which LPCAT (lysophosphocholine acyltransferase) produces PC from lyso-PC and fatty acids (Riekhof et al. 2007a; Hishikawa et al. 2008; Shindou et al. 2009) (see Fig. 2). In most mammalian cells, the majority of PC is formed through the CDPcholine pathway (Kennedy 1956; Gibellini and Smith 2010; Hermansson et al. 2011), and only in hepatocytes PE methylation is the predominant pathway (Sundler and Akesson 1975; $\mathrm{Li}$ et al. 2005). Reactions of the CDP-choline pathway are similar to the CDP-ethanolamine pathway and catalyzed by choline kinase, phosphocholine cytidyltransferase, and choline phosphotransferase. In the final step, phosphocholine is transferred from CDP-choline to DAG forming PC. In yeast (Boumann et al. 2004) as well as in mammals (Henneberry and McMaster 1999), enzymes of the both branches of the Kennedy pathway have overlapping substrate specificities.

The second pathway of PC production in mammalian cells (Van Pilsum and Carlson 1970) and yeast (Kodaki and Yamashita 1987) is PE methylation. In this sequence, S-adenosylmethionine (SAM) serves as methyl donor for three steps of methyltransferase reactions. In the first step, PE is methylated to monomethyl-PE and then further converted to dimethyl-PE in the second step. The biosynthetic sequence is completed by a third step of methylation yielding the final product PC. In yeast, the gene products of CHO2/PEM1 and OPI3/PEM2 are involved (Kodaki and Yamashita 1987), whereas hepatocytes harbor only one $\mathrm{N}$-methyltransferase, which catalyzes all three steps of PE methylation (Sundler and Akesson 1975; Ridgway et al. 1989). The lower eukaryote, Trypanosoma brucei, lacks genes coding for PE $N$-methyltransferases (Gibellini et al. 2009).

\section{CARDIOLIPIN AND \\ PHOSPHATIDYLGLYCEROL SYNTHESIS IN MITOCHONDRIA}

Synthesis of PG and CL in mitochondria occurs by a multistep reaction sequence (Schlame et al. 1993). First, PA is converted to CDP-DAG by
Cds1p, either in the ER/MAM or in mitochondria. Then, conversion of CDP-DAG to phosphatidylglycerol phosphate (PGP) catalyzed by Pgslp occurs (Chang et al. 1998a). PGP is dephosphorylated to $P G$ in a reaction that is accomplished by the PGP phosphatase Gep4p (Osman et al. 2010). In the final step of CL synthesis, a phosphatidate (PA) moiety is transferred from CDP-DAG to the hydroxyl group in the head group of PG. The cleavage of the pyrophosphate group provides the chemical energy for the latter reaction. In yeast (Jiang et al. 1997; Chang et al. 1998b; Tuller et al. 1998), Arabidopsis (Katayama et al. 2004; Nowicki et al. 2005), and human cells (Chen et al. 2006; Houtkooper et al. 2006; Lu et al. 2006), CL synthase was localized to mitochondria. Importantly, CL undergoes remodeling processes (Joshi et al. 2009; Schlame and Ren 2009) with so-called tafazzins (Malhotra et al. 2009) involved. Tafazzins are phospholipid transacylases that transfer acyl groups from phospholipids, preferentially PC, to monolysocardiolipin (MLCL). The reverse reaction of this modification is the transfer of an acyl group from CL to lyso-PC. The reaction does not require activation of fatty acids but occurs in a lysophospholipid-phospholipid complex by deprotonation and nucleophilic attack on the ester bond of the acyl donor (Xu et al. 2006).

PA and CDP-DAG are important intermediates not only for PG/CL synthesis but also for the formation of PI and PS (Athenstaedt and Daum 1999). In the yeast, PA is synthesized from glycerol-3-phosphate and/or dihydroxyacetone phosphate (DHAP) in the ER and lipid droplets by two steps of acylation. The first acetylation reaction with DHAP as a substrate leads to acyl-DHAP, which is then reduced by the 1-acyl-DHAP reductase Ayrlp in an NADPHdependent reaction to lyso-PA. Alternatively, acylation of glycerol-3-phosphate leads to formation of lyso-PA. In a final acylation step, lysoPA is converted to PA (Athenstaedt et al. 1999a; Sorger and Daum 2003). PA can also be generated by phospholipase D (Osman et al. 2011) in mitochondria. In plants, PA synthesis occurs in plastids, mitochondria, and microsomes. Dephosphorylation of PA is catalyzed 
Lipid Transport between the ER and Mitochondria

by mammalian lipin and the yeast ortholog Pah1p (Carman and Han 2006, 2009; Brindley et al. 2009; Harris and Finck 2011), which were recently shown to be pacemakers and switch points in lipid metabolism. Dephosphorylation of PA is a crucial step, because the product of the dephosphorylation reaction, DAG, becomes substrate for triacylglycerol synthases and thus promotes biogenesis of lipid droplets (Adeyo et al. 2011). PA, which is not dephosphorylated, is preferentially converted to CDP-DAG, which is further used for the synthesis of phospholipids. CDP-DAG synthase activity in yeast, as well as in mammals, was localized to the ER and mitochondria (Kuchler et al. 1986; Kelley and Carman 1987; Chen et al. 2006).

\section{PHOSPHATIDYLINOSITOL SYNTHESIS}

PI is produced in the ER and has to be imported into mitochondria. PI is synthesized from CDPDAG and inositol (Gardocki et al. 2005). In the yeast, deletion of the only phosphatidylinositol synthase gene PIS1 is lethal (Nikawa et al. 1987). Furthermore, PI serves as precursor for cell signaling molecules such as phosphatidylinositol phosphates (PIP), phosphatidylinositol bisphosphates (PIP2) and phosphatidylinositol triphosphates (PIP3) and for the biosynthesis of GPI anchors (Serricchio and Bütikofer 2011).

\section{TRANSPORT OF PHOSPHOLIPIDS BETWEEN THE ENDOPLASMIC RETICULUM AND MITOCHONDRIA}

As the biosynthetic sequence of PS-PE-PC synthesis occurs in different subcellular compartments (see above), the amounts of intermediates and products are indication and measure for transport between organelles. Therefore, interorganelle translocation of aminoglycerophospholipids can be investigated by following the incorporation of serine into PS in the ER, decarboxylation of PS to PE in the mitochondria, and methylation of PE to PC upon the return of $\mathrm{PE}$ to the ER without isolation of organelles. Making use of this experimental strategy, phospholipid transport studies with intact cells, isolated organelles, and permeabilized cells have been performed (Butler and Thompson 1975; Voelker 1985, 1989a,b, 1990, 1991; Vance 1990; Achleitner et al. 1995; Shiao et al. 1995; Emoto et al. 1999; Kuge et al. 2001; Schumacher et al. 2002; Wu and Voelker 2004; Carrasco et al. 2006; Riekhof and Voelker 2006; Kornmann et al. 2009; Nguyen et al. 2012; Padilla-López et al. 2012; Tamura et al. 2012). These studies showed that in mammalian cells PS transport from MAM to the OMM requires ATP. Further import of PS to the IMM yields PE (Voelker and Frazier 1986; Voelker 1990, 1991; Shiao et al. 1995).

Experiments with isolated organelles provided more detailed information about the process of phospholipid import into mitochondria. Reconstitution of transport systems using isolated mitochondria and microsomes/MAM (Kuchler et al. 1986; Simbeni et al. 1990; Vance 1990; Achleitner et al. 1999; Emoto et al. 1999) revealed that uptake of PS by mitochondria depended on the PS concentration in the donor membranes (ER, Golgi) (Wu and Voelker 2004). Although ATP was required for transport of PS in intact and permeabilized cells (see below), no such observation was made in the reconstituted in vitro system. It was argued that close apposition of donor (ER/MAM) and acceptor (mitochondria) membranes was sufficient for transport, but that ATP was probably required to provide appropriate conditions for transport of this phospholipid in intact cells. Experiments making use of the coisolation of MAM with mitochondria suggested that the contact of these two cellular fractions is fairly tight (Vance 1990; Achleitner et al. 1999). Altogether, it was concluded that membrane contact between ER and mitochondria is important for lipid translocation between these two organelles.

Experiments performed with permeabilized cells provided a useful alternative to the experiments described above (Lim et al. 1986; Voelker 1992; Achleitner et al. 1995; Kuge et al. 2001; Wu and Voelker 2001). Permeabilized cells are obtained by mild chemical or mechanical treatment of whole cells, resulting in the internal organelle structures remaining largely intact, while access to the interior is possible for 
compounds that cannot enter an intact cell. In permeabilized yeast cells (Achleitner et al. 1999) $\left[{ }^{3} \mathrm{H}\right]$ serine is incorporated into PS in the ER. Transport of $\left[{ }^{3} \mathrm{H}\right] \mathrm{PS}$ to mitochondria yields $\left[{ }^{3} \mathrm{H}\right] \mathrm{PE}$ formed by mitochondrial Psd1p. Use of $p s d 2 \Delta$ mutants and depletion of ethanolamine from the medium allows attribution of the formed $\left[{ }^{3} \mathrm{H}\right] \mathrm{PE}$ to transport of $\left[{ }^{3} \mathrm{H}\right] \mathrm{PS}$ from the ER. Transport of $\left[{ }^{3} \mathrm{H}\right] \mathrm{PE}$ from mitochondria to the ER results in formation of $\left[{ }^{3} \mathrm{H}\right] \mathrm{PC}$ as a measure for this transport route (Achleitner et al. 1995, 1999; Shiao et al. 1998).

The advantage of permeabilized cells is that reactions can be manipulated by addition of chemicals such as divalent ions, energy blockers, or cytoskeleton inhibiting reagents (Eilers et al. 1989) or by removing the cytosol. This feature allowed additional characterization of lipid transport between ER and mitochondria with mammalian (Voelker 1990) and yeast cells (Achleitner et al. 1995). Transport of PS to mitochondria was shown to be dependent on ATP in mammalian cells (Voelker 1989a) but not in yeast (Achleitner et al. 1999). However, a certain amount of ATP must be present in both cell types (Shiao et al. 1995) because upstream reactions of lipid precursor formation are energy consuming. It was also shown that ongoing synthesis of PS is not required for translocation to mitochondria because preformed PS was efficiently used as a substrate for mitochondrial PS decarboxylation. Interestingly, when exogenous mitochondria were added to permeabilized cells, they failed to serve as acceptors for PS import (Voelker 1993). This result suggests that pre-existing, stable associations between mitochondria and ER/MAM play an important role in the transport process.

In a yeast genetic screen, Voelker and coworkers searched for components that influence the translocation of PS from ER to the sites of decarboxylation in mitochondria (via Psd1p) (Schumacher et al. 2002) and Golgi/vacuoles (via Psd2p) (Trotter et al. 1998; Wu and Voelker 2001, 2004). The first gene product identified was Met30p, which influenced the import of PS into mitochondria. MET30 encodes a subunit of a multicomponent E3 ubiquitin ligase (Aghajan et al. 2010; Ouni et al. 2010) and af- fects substrate specificity of the ubiquitin ligase (Chandrasekaran et al. 2006; Yan and Xiong 2010). One substrate for the E3 ubiquitin ligase is the transcription factor Met4p, which is inactivated upon ubiquitination. It was suggested that Met30p mediates ubiquitination of certain target proteins and may play a role either in ERmitochondria recognition, in the inhibition of this docking process, or in regulation of transcription of a factor involved in lipid transport. The second component identified in the screen was the phosphatidylinositol 4-kinase Stt4p, which affects transport of PS to the site of Psd2p-driven conversion to PE (Trotter et al. 1998). The mode of action of Stt4p on organelle interaction and/or PS translocation remains to be elucidated. It was suggested that the $\mathrm{C} 2 \mathrm{do}$ main of Psd2p, which binds $\mathrm{Ca}^{2+}$, interacts with proteins or lipids and recognizes anionic lipids such as PS and polyphosphoinositides (Choi et al. 2005) and may be the bridge for PS translocation. Finally, the gene product of PDR17/ SFH4 was found to affect PS transport to Psd2p. Reconstitution assays with permeabilized cells and isolated organelles showed that Pdr17p must be present on the acceptor membrane for transfer of PS to Psd2p (van den Hazel et al. 1999; Wu et al. 2000). The mechanism of action of Pdr17p is still unknown.

Reconstitution of PS synthesis and transport in permeabilized mammalian cells identified two other components that affect PS transport from the ER/MAM to mitochondria (Emoto et al. 1999; Kuge et al. 2001). One of these proteins is S100B (NP_006236), an EFhand domain- $\mathrm{Ca}^{2+}$-binding protein. It is not known whether this protein participates in transport or promotes stability and/or assembly of interactions of ER/MAM and mitochondria. The second component was only indirectly identified in the mammalian cell line R41, which has a defect in PS transport between the OMM and IMM.

Studies with isolated organelles treated with protease (Shiao et al. 1998; Achleitner et al. 1999) or dinitrophenol, which alters the distance between the ER and mitochondria (Hovius et al. 1992), suggested the participation of organelle surface proteins in PS transport. 
Electron microscopy supported this view by demonstrating close contact zones between ER/MAM and mitochondria, which might serve as bridges for lipid translocation (Csordás et al. 2006). Furthermore, the involvement of acetylated microtubules in ER-mitochondria dynamics was demonstrated, a mechanism by which membrane contact can be established and/or maintained (Friedman et al. 2010). Moreover, mitochondrial division sites produced by Dnm1p and Drp1p were found to be physically connected with the ER (Friedman et al. 2011).

To shed more light on the role of ER-mitochondria contact, genetic and synthetic genetic interactions analysis mainly with the yeast, Saccharomyces cerevisiae, were performed (Birner et al. 2003; Kornmann et al. 2009; Osman et al. 2009a). Such genetic screens were designed in a way that defects in two or more interacting gene products become lethal. Recently, Kornmann et al. (2009) identified components of ER-mitochondria contact in yeast at the molecular level. They showed that in wild-type cells, a protein complex tethers the ER/MAM and mitochondria. Mutations in this protein complex caused slow growth or were lethal for the cells, but could be suppressed by an artificial tethering construct called ChiMERA, which carried a GFP molecule. When staining the mitochondria with mito-tracker and expressing the ChiMERA, association was visualized confirming that ChiMERA acted as a bridge between the ER and mitochondria. The authentic complex was named ERMES (ER mitochondria encountered structures) and contains the OMM proteins, Mdm10p, Mdm12p, and Mdm34p, which interact with the ER membrane anchored protein $\mathrm{Mmm} 1 \mathrm{p}$. In the absence of ERMES, the CL level and the PS/PC conversion rates were decreased, suggesting the involvement of ERMES in phospholipids transport between ER and mitochondria (Fig. 3). Moreover, genetic interactions between PSD1, GEM1, and the ERMES complex were shown (Kornmann et al. 2009). The $\mathrm{Ca}^{2+}$ Miro (mitochondria rho-like) GTPase Gemlp is a regulatory component of ERMES (Kornmann et al. 2011; Stroud et al. 2011), maintains mitochondrial morphology and in-
Lipid Transport between the ER and Mitochondria

heritance (Frederick et al. 2004, 2008) and most likely connects ERMES to the actin cytoskeleton (Kornmann et al. 2011; Michel and Kornmann 2012). It was assumed that Gem1p shuttles between a free and ERMES bound form (see Fig. 3), although the molecular mechanism of Gem1p remains unknown. Physical interaction of Psd1p with ERMES or Gem1p was not demonstrated. Nevertheless, it was reported that a gem $1 \Delta p s d 2 \Delta d p l 1 \Delta$ yeast mutant grown on a nonfermentable carbon source was defective in its PC synthesis (Kornmann et al. 2011), most likely by impaired PE and PS transport. A similar growth phenotype was reported before for the gem $1 \Delta$ single deletion strain grown on synthetic glycerol media (Frederick et al. 2008). GEM1 also shows strong synthetic lethality with GEP4, encoding a PGP phosphatase (Kornmann et al. 2011). Gem1p is well conserved in the eukaryotic kingdom, suggesting that Miro GTPases are general components of ER-mitochondria connections. Miro-1, the mammalian homolog of Gem1p, interacts with mitofusin 1 and 2, the human homologs of yeast Fzolp. Mfn-2 was suggested to tether mitochondria to ER and being involved in mitochondrial movement along axons (de Brito and Scorrano 2008; Misko et al. 2010). Most recently, however, the role of ERMES and Gem1p in the import of PS into mitochondria and its conversion to PE was challenged (Nguyen et al. 2012). It was argued that, despite their genetic and physical interaction, ERMES and Gem1p function in distinct pathways, and the absence of ERMES and Gem1p had only little effect on PS import into mitochondria and conversion to PE. The effect on PC formation as described by Kornmann et al. (2009) was regarded as minor. Nguyen et al. (2012) argued that changes in the lipid profile of cells lacking ERMES were side effects of defects in mitochondrial morphology.

Recently, another mitochondrial complex named MitOS, MICOS, or MINOS was identified (Harner et al. 2011; Hoppins et al. 2011; von der Malsburg et al. 2011). This IMM-associated complex functions in cristae formation and morphology (Rabl et al. 2009). It was proposed (van der Laan et al. 2012) that MINOS forms the central core of a large and complex 


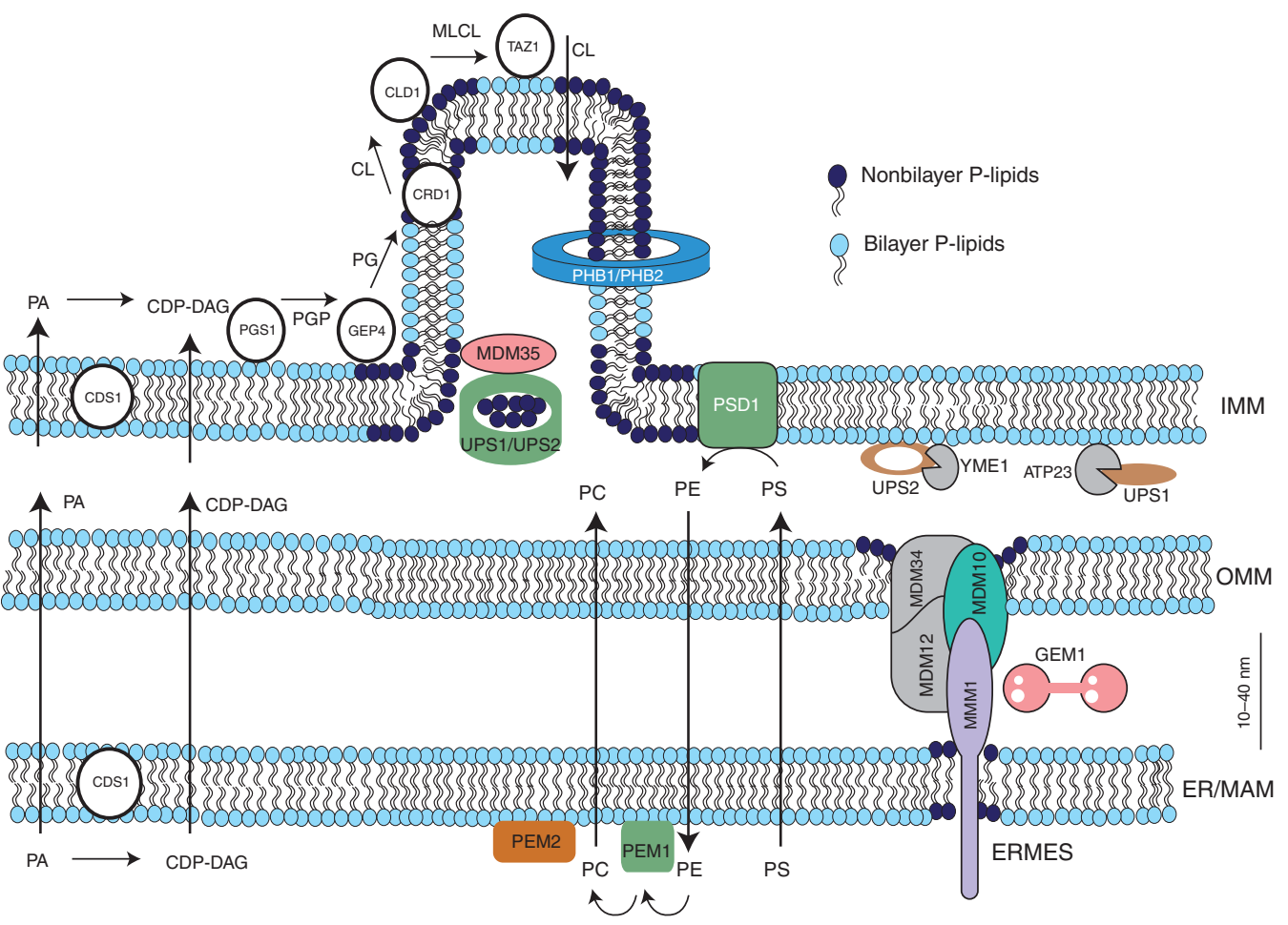

Figure 3. Components involved in translocation of phospholipids to and within mitochondria of yeast. The directions of lipid translocation are indicated by arrows. While PS and PC are imported into mitochondria, a large portion PE is exported. Upon import the majority of PS is converted to PE by Psd1p. Decarboxylation of PS to PE in mitochondria and methylation of PE to PC in the ER are sufficient for supplying cells with PE and PC even in the absence of external ethanolamine or choline. Similar to PS and PC, PA and CDP-DAG also have to be imported into mitochondria where they are required for CL synthesis. The pathway of CL synthesis in the IMM starts with CDP-DAG and is completed during several steps by a multienzyme cascade. A small portion of CL is exported to the OMM. The ERMES complex containing gene products of MDM10, MDM34, MDM12, and MMM1 tethers ER and mitochondria. In mammalian cells, Mfn1/2 seem to have a similar function. ERMES associates with the GTPase GEM1, cycling between ERMES bound and free form. UPS1/UPS2 interact with Mdm35p and regulate the mitochondrial levels of PE and CL. UPS1 and UPS2 are degraded by ATP23 and YEM1, respectively. Prohibitin ringlike structures made from two proteins $\mathrm{PHB} 1 / 2$ contribute to the formation of PE and CL clusters in the IMM. For a detailed description of biosynthetic and translocation processes and components involved, see text.

organizing system named ERMIONE, which includes the ERMES complex, the prohibitin ringlike structures, the TOM and TIM complexes, and $\mathrm{Mdm} 31 / 32$ proteins required for mtDNA maintenance. MINOS was also found to interact with the protein VDAC and with the fusion protein Ugol (van der Laan et al. 2012). Both ERMES and MINOS are genetically linked to the prohibitin ring complexes of the IMM that are integrated into the lipid network metabolism (Psd1, Ups1/Ups2) (Birner et al. 2003; Gohil et al. 2005; Kornmann et al. 2009; Osman et al. 2009a; Tamura et al. 2009, 2012; Potting et al. 2010). However, direct involvement of MINOS in lipid transport and/or assembly into mitochondrial membrane has not been demonstrated.

\section{LINK BETWEEN CARDIOLIPIN FORMATION AND INTRAMITOCHONDRIAL TRANSPORT OF AMINOGLYCEROPHOSPHOLIPIDS}

A link between CL and PE assembly in mitochondrial membranes, PE synthesis by Psd1p, 
Lipid Transport between the ER and Mitochondria

and the role of prohibitins was uncovered in synthetic lethal screens with the yeast (Birner et al. 2003; Gohil et al. 2005). It was shown that a $p h b 1 \Delta p h b 2 \Delta p s d 1 \Delta$ triple mutation was lethal due to reduced PE levels and loss of mtDNA. Osman et al. (2009a) demonstrated that ringlike prohibitin complexes organize CL and PE in clusters in the IMM and become essential in strains with low levels of PE and CL. This finding supported the view of physical similarities of CL and PE and their importance for mitochondria morphology (Osman et al. 2011; Joshi et al. 2012). In subsequent work, 35 genetic interactions of prohibitins (GEP) were identified, which were required for cell survival in the absence of prohibitins. Among the genes detected, UPS1, GEP1/UPS2, PSD1, MDM35, MMM1, GEP4, and CRD1 were prominent (Osman et al. 2009b) (see Fig. 3). Prohibitins seem to control IMM organization and integrity by acting as lipid scaffolds for PE and CL (Osman et al. 2009a,b). Ups1p and Ups2p antagonistically regulate the CL (Tamura et al. 2009) level, and Ups 2 p also regulates the PE level (Potting et al. 2010) in the IMM. Most recently, it was shown that Ups1p promotes conversion of PE to PC, whereas Ups2p suppresses this process ( Tamura et al. 2012). It was concluded that UPS proteins affect export of PE from the IMM, although the mechanism of this regulation is unknown. The authors showed that loss of Ups1, the ERMES complex, and Mdm31p caused similar defects in mitochondria, especially in CL and PE homeostasis in the IMM. Yeast Ups1p and Ups $2 \mathrm{p}$ are per se unstable proteins and degraded by the proteases Ymelp and Atp23p in the IMM (Potting et al. 2010). The newly identified protein Mdm35p protects them from proteolytic degradation (Tamura et al. 2009, 2012; Potting et al. 2010).

\section{IMPORT OF PHOSPHATIDYLCHOLINE AND PHOSPHATIDYLINOSITOL INTO MITOCHONDRIA}

Although PC and PI are major phospholipids of mitochondrial membranes, little is known about their import into this organelle. Both phospholipids are synthesized in the ER from where they are translocated to mitochondria and assembled into membranes. Lampl et al. (1994) designed an in vitro assay to study the import of $\left[{ }^{3} \mathrm{H}\right]$-labeled PI and PC from unilamellar donor vesicles to isolated yeast mitochondria. Both phospholipids ended up in the IMM. During import, they were detected in contact sites between OMM and IMM, supporting the notion that these sites are involved in intramitochondrial phospholipid transport. The uncoupler CCCP, the antibiotic adriamycin, and energy depletion did not inhibit this process. Janssen et al. (1999) described transbilayer movement of PC in isolated OMM vesicles from yeast. They showed that this translocation was rapid and bidirectional. Pretreatment of the OMM with proteinase $\mathrm{K}$ or sulfhydryl reagents had no effect on PC transport.

\section{STEROLS AND SPHINGOLIPIDS OF MITOCHONDRIA}

Sterols and sphingolipids are minor lipid components of mitochondria. Both lipid classes are synthesized in extramitochondrial compartments and need to be imported and assembled into mitochondrial membranes. Sterol biosynthesis is accomplished by a complex sequence of reactions that are localized to the ER and peroxisomes of mammalian cells (Ikonen 2008; Miller and Auchus 2011; Miller and Bose 2011). In mammalian cells, cholesterol is the end product of this biosynthetic pathway (Soccio and Breslow 2004; Brown and Goldstein 2009), whereas in yeast ergosterol is the major sterol (Wagner and Daum 2005; Jacquier and Schneiter 2012). In yeast, the ER and lipid droplets contribute to sterol biosynthesis (Leber et al. 1994; Athenstaedt et al. 1999b). Plants produce a variety of sterols such as phytosterols (Suzuki and Muranaka 2007). In mammalian mitochondria the majority of cholesterol is localized to the OMM (Daum 1985), whereas in yeast (SperkaGottlieb et al. 1988; Wriessnegger et al. 2009) most of the mitochondrial sterol was found in the IMM.

Biosynthesis of sphingolipids occurs in the ER and in organelles along the protein secretory pathway, mainly the Golgi (Perry and Ridgway 
2005; Breslow and Weissman 2010; Levy and Futerman 2010; Mencarelli et al. 2010). However, recent work showed the presence of ceramide metabolic enzymes in mitochondria from mammals and yeast (Kitagaki et al. 2007; Novgorodov et al. 2011). The majority of this lipid class is located to the plasma membrane, whereas amounts in mitochondria are minor (Breslow and Weissman 2010; Stiban et al. 2010; van Meer and Hoetzl 2010). In the OMM, the concentration of ceramide is threefold higher than in the IMM (Mencarelli et al. 2010).

\section{IMPORT OF STEROLS INTO MITOCHONDRIA}

Sterols in mitochondria may serve as structural components of membranes and/or as precursors for hormone synthesis. For both purposes, they have to be imported into mitochondria. Transport of sterols from the ER to mitochondria appears to occur by machinery, which is different from that described for phospholipids. A nonvesicular and a vesicular pathway have been proposed for cholesterol translocation to mitochondria (Maxfield and Wüstner 2002).

A number of components appear to contribute to sterol transport to mitochondria (Fig. 4). The best studied protein of this kind is the so-called steroidogenic acute regulatory protein (StAR) (Clark et al. 1994). StAR is almost exclusively expressed in steroid-producing cells and regulated by cAMP (Strauss et al. 1999; Benmessahel et al. 2002). StAR requires ATP and an electrochemical gradient for maximal activity (King and Stocco 1996). Import of StAR into mitochondria results in cleavage of an amino-terminal mitochondrial targeting sequence (Arakane et al. 1998). The carboxyl-terminus of StAR displays cholesterol transferring capacity (Strauss et al. 1999; Stocco 2000). Ligand binding to StAR changes its secondary structure; the protein itself alters the domain structure of the OMM to facilitate rapid sterol transfer (Petrescu et al. 2001). StAR interacts with the cAMP-dependent protein kinase (PKA) and a peripheral-type benzodiazepine receptor (PBR) (Hauet et al. 2002), which was later named TSPO (translocator protein) (Mukhin et al. 1989; Krueger and Papadopoulos 1990). A protein named PAP7 was identified as a regulator of PBR and PKA. PBR/TSPO (translocator protein) was shown to support import and processing of StAR in the mitochondria (Hauet et al. 2005). VDAC (voltage-dependent anion channel) and ANT (adenine nucleotide transporter) were identified as interaction partners of PBR/ TSPO (McEnery et al. 1992; Rone et al. 2009). VDAC binds cholesterol and influences its mitochondrial distribution (Campbell and Chan 2007). It appears that TSPO and VDAC together with TOM (translocase of the OMM) function in StAR assembly into mitochondria. Also members of the ACBD family, ACBD1 and ACBD3/ PAP7, seem to participate in the function of the transduceosome (Midzak et al. 2011). Finally, a protein named MLN64 (metastatic lymph node protein 64) with a carboxy-terminal START domain for cholesterol binding was identified as a mediator for cholesterol transport from late endosomes to the plasma membrane and also to mitochondria (Zhang et al. 2002; Charman et al. 2010; Liapis et al. 2012). It was shown that in Niemann-Pick Type C (NPC) mutated cells, MLN64 supplies cholesterol from endosomes to mitochondria. In analogy to StAR, MLN64 needs direct contact with mitochondria to transfer cholesterol, indicating that direct contact between endosomes and mitochondria may occur (Charman et al. 2010).

Once cholesterol has been imported into mitochondria, it is further converted to steroids (Miller and Auchus 2011) (see Fig. 4). The first and rate-limiting step in steroidogenesis is the conversion of cholesterol to pregnenolone by a cytochrome P450. Further conversion requires the action of hydroxysteroid dehydrogenases. Steroidogenic cells in humans are localized to a variety of tissues, most prominently to adrenal glands and gonads. In the adrenal glands, mainly the conversion of cholesterol to aldosterol, dehydroepiandrosterone (DHEA), and cortisol-like is catalyzed. In the gonal glands, cholesterol is converted to steroid hormones, namely estradiol in the ovarian granulose cells and to testosterone by the testicular leyding cells (Miller and Auchus 2011). 
A

Cytosol
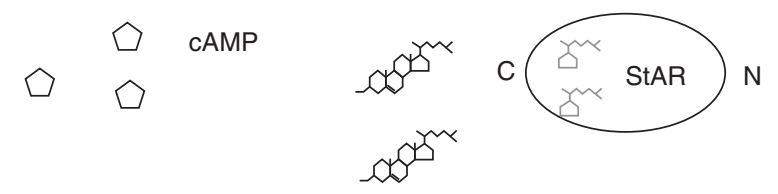

C

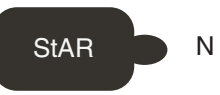

B

Cytosol

OMM

IMM

Matrix

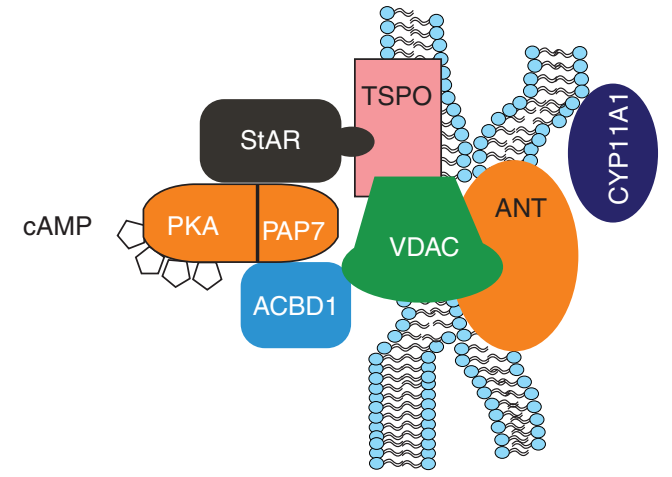

C

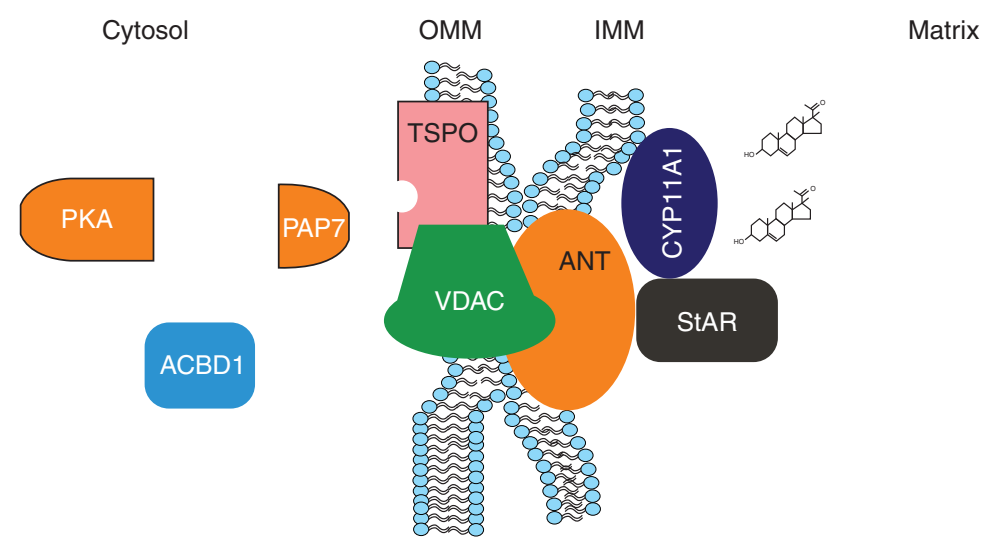

Figure 4. Import of sterols into mitochondria for steroidogenesis. (A) Upon binding of cholesterol the StAR precursor protein changes its conformation. StAR expression is regulated by cAMP. $(B)$ StAR comes in contact with PKA, PAP7/ACBD3, and ACBD1 and is imported into the mitochondria with sterols bound. Upon interaction with TSPO, StAR induces changes in the OMM and a transduceosome is formed. This structure, which includes TSPO/VDAC of the OMM and ANT in the IMM, facilitates imports and maturation of StAR. (C) Upon arrival in the mitochondrial matrix, the mature StAR protein delivers cholesterol to CPY11A1 where it is converted to pregnenolone.

Evidence about import of sterols in nonsteroidogenic cells is rare. Import of radiolabeled ergosterol and cholesterol from unilamellar vesicles into isolated mitochondria has been studied in Saccharomyces cerevisiae (Tuller and
Daum 1995). Supply of ergosterol to the mitochondrial surface was enhanced by a cytosolic fraction, whereas no such additive was required for cholesterol transport. Both sterols reached the IMM in an energy-independent process 
V.V. Flis and G. Daum

but accumulated to some extent in contact sites between OMM and IMM, supporting the idea that these zones are sites of intramitochondrial lipid translocation.

\section{SPHINGOLIPID INCORPORATION INTO MITOCHONDRIA}

Little is known about import and function of sphingolipids in mitochondria. There is evidence that sphingolipid metabolism affects the mitochondrial pathway of apoptosis (Chipuk et al. 2012). Ceramides with their short and long acyl-chains could form large protein-permeable channels in the OMM (Siskind and Colombini 2000), and such channels may contribute to the release of proapoptotic proteins from mitochondria (Futerman 2006). It was proposed that ceramide is produced by hydrolysis of sphingomyelin by a neutral sphingomyelinase in MAM (Chipuk et al. 2012; Mullen et al. 2012) and then transferred to mitochondria where it is converted to sphingosine-1phosphate and hexadecenal. It has also been proposed that in liver mitochondria, thioesterase and neutral ceramidase produce ceramide from sphingosine and acyl-CoA (Novgorodov and Gudz 2009; Novgorodov et al. 2011). In vitro, ceramide synthase, or reverse ceramidase activity was detected in mitochondria (Bionda et al. 2004). In yeast, Isc1p has been suggested to generate ceramides in mitochondria (Kitagaki et al. 2007, 2009).

Evidence for the existence of two ceramide transporting proteins has been presented: the Goodpasture antigen-binding protein (GPBP) and its splice variant, the ceramide transporter (CERT) (Mencarelli et al. 2010). It was proposed that these proteins might be involved in mitochondrial lipid homeostasis, although this view is still a matter of debate.

\section{CONCLUSIONS}

Among the different subcellular compartments, mitochondria are one of the most unique when considering lipid composition. Presence of PG and CL, as well as the large amount of PE, is characteristic for mitochondrial membranes.
Recent studies have shown that especially these nonbilayer forming lipids are important for mitochondrial function (Birner et al. 2003; Gohil et al. 2005; Nebauer et al. 2007; Osman et al. 2009a; Acehan et al. 2011; Joshi et al. 2012; Tamura et al. 2012). However, low abundant lipids in mitochondria such as sterols or sphingolipids must not be ignored, although at present ascribing specific functions to these components in mitochondria is difficult.

Large amounts of lipids have to be imported into mitochondria. Different mechanisms of intracellular lipid transport have been discussed for several decades (Daum and Vance 1997; Holthuis and Levine 2005; Voelker 2005; Schulz and Prinz 2007; Osman et al. 2011). The role of lipid transfer proteins, which were enthusiastically studied in the beginning of these investigations, has been scrutinized more recently. Such transfer proteins may be more relevant for lipid sorting or sensing than bulk lipid transport. Vesicle flux was recognized as a more potent mechanism of lipid transport because it allows rapid, robust, and efficient translocation to target membranes. It appears that at least significant portions of lipids are cotransported to the cell periphery by the classical pathway of protein secretion (Salama and Schekman 1995; Kohlwein et al. 1996). However, other types of vesicles may also be relevant although experimental evidence for such processes is missing. Last but not least, membrane contact has become an attractive alternative for intracellular lipid translocation (Levine and Loewen 2006; Lebiedzinska et al. 2009; Voelker 2009; de Brito and Scorrano 2010; Elbaz and Schuldiner 2011; Osman et al. 2011). Contact of the ER with mitochondria through the MAM fraction, association of the ER with the plasma membrane or nuclear-vacuolar junctions became prominent examples of this kind. Finally, transmembrane movements of lipids by translocases and flippases contribute to appropriate lipid distribution in organelles (Holthuis and Levine 2005).

Close proximity of ER and mitochondria as shown by electron microscopy (Csordás et al. 2006; Friedman et al. 2011) supports the idea of lipid transport by membrane contact. 
The distance is sufficient for a protein complex to bridge the gap between organelles and to connect membranes without causing fusion (Achleitner et al. 1999). A hemistalk structure caused by high amounts of mitochondrial PE and $\mathrm{CL}$, which provide negative membrane curvature, may support attachment and point fusion events (Chernomordik and Kozlov 2005, 2008; Chernomordik et al. 2006). Protein bridges like ERMES stabilize the energy-unfavorable state (Kozlov et al. 2010). Microtubules and actin filaments may help by bridging ER and mitochondria and establishing or maintaining protein contact between membranes (Friedman et al. 2010, 2011). Although ERMES and associated proteins were shown to create or maintain contact between ER and mitochondria (Kornmann et al. 2009; Stroud et al. 2011), direct functions of these components in lipid transport were scrutinized (Nguyen et al. 2012). It was argued that ERMES facilitates membrane contact, but other components may be more directly involved in lipid translocation. MAM-OMM contact sites appear to be further linked to complexes of the IMM (de Brito and Scorrano 2008; Kornmann et al. 2009). Transport of lipids from OMM to IMM may occur either by membrane contact or by translocation through the intermembrane space. Despite its role in IMM organization the cristae-forming MINOS complex (Harner et al. 2011; Hoppins et al. 2011; van der Laan et al. 2012) is most likely not involved in this process. The role of Gem1p and Ups-proteins in OMM-IMM lipid translocation has to be taken into account (Tamura et al. 2012). Interaction of prohibitins with the mitochondrial lipid synthesizing machinery also appears to be important for lipid homeostasis in this organelle (Birner et al. 2003; Gohil et al. 2005; Gohil and Greenberg 2009; Osman et al. 2009a,b).

An intriguing although unsolved question is regulation of lipid transport to/from and within mitochondria. Fluidity of the membrane or membrane curvature affected by PE and CL are parameters that may influence biophysical properties of the membrane environment. Also the acyl chain length of specific phospholipid species could have an effect (Dolis et al. 1996;
Lipid Transport between the ER and Mitochondria

Heikinheimo and Somerharju 1998; Kevala and Kim 2001). A balanced concentration of phospholipids, sterols, and sphingolipids appears to be important for membrane fusion or fission. In that respect, the low-abundant lipids in mitochondria such as sterols or sphingolipids may be relevant. Regulation of the mitochondrial lipid assembly by Ups1p and Ups2p, which are in turn subject to proteolytic degradation/protection by Yme1p, Atp23p, and Mdm35p (Potting et al. 2010; Tamura et al. 2012) are examples for the widespread network of lipid assembly and homeostasis in mitochondrial membranes, which we are just beginning to understand in more detail at the molecular level.

\section{ACKNOWLEDGMENTS}

We thank Susanne Horvath and Edina Harsay for critically reading this manuscript. This work is financially supported by the FWF (DK Molecular Enzymology W901-B05 and project P21429 to G.D.).

\section{REFERENCES}

Acehan D, Malhotra A, Xu Y, Ren M, Stokes DL, Schlame M. 2011. Cardiolipin affects the supramolecular organization of ATP synthase in mitochondria. Biophys J 100: 2184-2192.

Achleitner G, Zweytick D, Trotter PJ, Voelker DR, Daum G. 1995. Synthesis and intracellular transport of aminoglycerophospholipids in permeabilized cells of the yeast, Saccharomyces cerevisiae. J Biol Chem 270: 29836 29842.

Achleitner G, Gaigg B, Krasser A, Kainersdorfer E, Kohlwein SD, Perktold A, Zellnig G, Daum G. 1999. Association between the endoplasmic reticulum and mitochondria of yeast facilitates interorganelle transport of phospholipids through membrane contact. Eur J Biochem 264: 545-553.

Adeyo O, Horn PJ, Lee S, Binns DD, Chandrahas A, Chapman KD, Goodman JM. 2011. The yeast lipin orthologue Pahlp is important for biogenesis of lipid droplets. J Cell Biol 192: 1043-1055.

Aghajan M, Jonai N, Flick K, Fu F, Luo M, Cai X, Ouni I, Pierce N, Tang X, Lomenick B, et al. 2010. Chemical genetics screen for enhancers of rapamycin identifies a specific inhibitor of an SCF family E3 ubiquitin ligase. Nat Biotechnol 28: 738-742.

Arakane F, Kallen CB, Watari H, Stayrook SE, Lewis M, Strauss JF 3rd. 1998. Steroidogenic acute regulatory protein (StAR) acts on the outside of mitochondria to stimulate steroidogenesis. Endocr Res 24: 463-468. 
V.V. Flis and G. Daum

Athenstaedt K, Daum G. 1999. Phosphatidic acid, a key intermediate in lipid metabolism. Eur J Biochem 266: $1-16$.

Athenstaedt K, Weys S, Paltauf F, Daum G. 1999a. Redundant systems of phosphatidic acid biosynthesis via acylation of glycerol-3-phosphate or dihydroxyacetone phosphate in the yeast Saccharomyces cerevisiae. J Bacteriol 181: $1458-1463$.

Athenstaedt K, Zweytick D, Jandrositz A, Kohlwein SD, Daum G. 1999b. Identification and characterization of major lipid particle proteins of the yeast Saccharomyces cerevisiae. J Bacteriol 181: 6441-6448.

Benmessahel Y, Guennoun R, Cadepond F, Baulieu EE, Schumacher M, Groyer G. 2002. Expression of steroidogenic acute regulatory protein in cultured Schwann cells and its regulation by cAMP. Ann NYAcad Sci 973: 83-87.

Bionda C, Portoukalian J, Schmitt D, Rodriguez-Lafrasse C, Ardail D. 2004. Subcellular compartmentalization of ceramide metabolism: MAM (mitochondria-associated membrane) and/or mitochondria? Biochem J 382: 527-533.

Birner R, Bürgermeister M, Schneiter R, Daum G. 2001. Roles of phosphatidylethanolamine and of its several biosynthetic pathways in Saccharomyces cerevisiae. Mol Biol Cell 12: 997-1007.

Birner R, Nebauer R, Schneiter R, Daum G. 2003. Synthetic lethal interaction of the mitochondrial phosphatidylethanolamine biosynthetic machinery with the prohibitin complex of Saccharomyces cerevisiae. Mol Biol Cell 14: 370-383.

Bogdanov M, Mileykovskaya E, Dowhan W. 2008a. Lipids in the assembly of membrane proteins and organization of protein supercomplexes: Implications for lipid-linked disorders. Subcell Biochem 49: 197-239.

Bogdanov M, Xie J, Heacock P, Dowhan W. 2008b. To flip or not to flip: Lipid-protein charge interactions are a determinant of final membrane protein topology. J Cell Biol 182: 925-935.

Boumann HA, de Kruijff B, Heck AJR, de Kroon AIPM. 2004. The selective utilization of substrates in vivo by the phosphatidylethanolamine and phosphatidylcholine biosynthetic enzymes Eptlp and Cpt1p in yeast. FEBS Lett 569: 173-177.

Breslow DK, Weissman JS. 2010. Membranes in balance: Mechanisms of sphingolipid homeostasis. Mol Cell 40: 267-279.

Brindley DN, Pilquil C, Sariahmetoglu M, Reue K. 2009. Phosphatidate degradation: Phosphatidate phosphatases (lipins) and lipid phosphate phosphatases. Biochim Biophys Acta 1791: 956-961.

Brown MS, Goldstein JL. 2009. Cholesterol feedback: From Schoenheimer's bottle to Scap's MELADL. J Lipid Res $\mathbf{5 0}$ (Suppl): S15-S27.

Bürgermeister M, Birner-Grünberger R, Nebauer R, Daum G. 2004. Contribution of different pathways to the supply of phosphatidylethanolamine and phosphatidylcholine to mitochondrial membranes of the yeast Saccharomyces cerevisiae. Biochim Biophys Acta 1686: 161-168.

Butler MM, Thompson W. 1975. Transfer of phosphatidylserine from liposomes or microsomes to mitochondria. Stimulation by a cell supernatant factor. Biochim Biophys Acta 388: 52-57.
Campbell AM, Chan SHP. 2007. The voltage dependent anion channel affects mitochondrial cholesterol distribution and function. Arch Biochem Biophys 466: 203-210.

Cao J, Shan D, Revett T, Li D, Wu L, Liu W, Tobin JF, Gimeno RE. 2008. Molecular identification of a novel mammalian brain isoform of acyl-CoA:lysophospholipid acyltransferase with prominent ethanolamine lysophospholipid acylating activity, LPEAT2. J Biol Chem 283: 19049-19057.

Carman GM, Han G-S. 2006. Roles of phosphatidate phosphatase enzymes in lipid metabolism. Trends Biochem Sci 31: 694-699.

Carman GM, Han G-S. 2009. Phosphatidic acid phosphatase, a key enzyme in the regulation of lipid synthesis. J Biol Chem 284: 2593-2597.

Carrasco MP, Jiménez-López JM, Martinez-Dueñas L, Ubiña S, Segovia JL, Marco C. 2006. Ethanol specifically alters the synthesis, acylation and transbilayer movement of aminophospholipids in rat-liver microsomes. Life Sci 78: $2781-2786$.

Chandrasekaran S, Deffenbaugh AE, Ford DA, Bailly E, Mathias N, Skowyra D. 2006. Destabilization of binding to cofactors and SCFMet30 is the rate-limiting regulatory step in degradation of polyubiquitinated Met4. Mol Cell 24: 689-699.

Chang SC, Heacock PN, Clancey CJ, Dowhan W. 1998a. The PEL1 gene (renamed PGS1) encodes the phosphatidylglycerophosphate synthase of Saccharomyces cerevisiae. J Biol Chem 273: 9829-9836.

Chang SC, Heacock PN, Mileykovskaya E, Voelker DR, Dowhan W. 1998b. Isolation and characterization of the gene (CLS1) encoding cardiolipin synthase in Saccharomyces cerevisiae. J Biol Chem 273: 14933-14941.

Charman M, Kennedy BE, Osborne N, Karten B. 2010. MLN64 mediates egress of cholesterol from endosomes to mitochondria in the absence of functional NiemannPick Type C1 protein. J Lipid Res 51: 1023-1034.

Chen D, Zhang X-Y, Shi Y. 2006. Identification and functional characterization of hCLS1, a human cardiolipin synthase localized in mitochondria. Biochem J 398: 169176.

Chernomordik LV, Kozlov MM. 2005. Membrane hemifusion: Crossing a chasm in two leaps. Cell 123: 375-382.

Chernomordik LV, Kozlov MM. 2008. Mechanics of membrane fusion. Nat Struct Mol Biol 15: 675-683.

Chernomordik LV, Zimmerberg J, Kozlov MM. 2006. Membranes of the world unite! J Cell Biol 175: 201-207.

Chipuk JE, McStay GP, Bharti A, Kuwana T, Clarke CJ, Siskind LJ, Obeid LM, Green DR. 2012. Sphingolipid metabolism cooperates with BAK and BAX to promote the mitochondrial pathway of apoptosis. Cell 148: 9881000.

Choi J-Y, Wu W-I, Voelker DR. 2005. Phosphatidylserine decarboxylases as genetic and biochemical tools for studying phospholipid traffic. Anal Biochem 347: $165-$ 175.

Choi J-Y, Augagneur Y, Ben MC, Voelker DR. 2012. Identification of gene encoding Plasmodium knowlesi phosphatidylserine decarboxylase by genetic complementation in yeast and characterization of in vitro maturation of encoded enzyme. J Biol Chem 287: 222-232. 
Clark BJ, Wells J, King SR, Stocco DM. 1994. The purification, cloning, and expression of a novel luteinizing hormone-induced mitochondrial protein in MA-10 mouse Leydig tumor cells. Characterization of the steroidogenic acute regulatory protein (StAR). J Biol Chem 269: 2831428322.

Cowan AK. 2009. Plant growth promotion by 18:0-lysophosphatidylethanolamine involves senescence delay. Plant Signal Behav 4: 324-327.

Csordás G, Renken C, Várnai P, Walter L, Weaver D, Buttle KF, Balla T, Mannella CA, Hajnóczky G. 2006. Structural and functional features and significance of the physical linkage between ER and mitochondria. $J$ Cell Biol 174: 915-921.

Daum G. 1985. Lipids of mitochondria. Biochim Biophys Acta 822: 1-42.

Daum G, Vance JE. 1997. Import of lipids into mitochondria. Prog Lipid Res 36: 103-130.

Davidson JB, Stanacev NZ. 1971. Biosynthesis of cardiolipin in mitochondria isolated from guinea pig liver. Biochem Biophys Res Commun 42: 1191-1199.

de Brito OM, Scorrano L. 2008. Mitofusin 2 tethers endoplasmic reticulum to mitochondria. Nature 456: 605610.

de Brito OM, Scorrano L. 2010. An intimate liaison: Spatial organization of the endoplasmic reticulum-mitochondria relationship. EMBO J 29: 2715-2723.

Delhaize E, Hebb DM, Richards KD, Lin JM, Ryan PR, Gardner RC. 1999. Cloning and expression of a wheat (Triticum aestivum L.) phosphatidylserine synthase cDNA. Overexpression in plants alters the composition of phospholipids. J Biol Chem 274: 7082-7088.

Deng L, Fukuda R, Kakihara T, Narita K, Ohta A. 2010. Incorporation and remodeling of phosphatidylethanolamine containing short acyl residues in yeast. Biochim Biophys Acta 1801: 635-645.

Dolis D, de Kroon AI, de Kruijff B. 1996. Transmembrane movement of phosphatidylcholine in mitochondrial outer membrane vesicles. J Biol Chem 271: 11879-11883.

Dolman NJ, Gerasimenko JV, Gerasimenko OV, Voronina SG, Petersen OH, Tepikin AV. 2005. Stable Golgi-mitochondria complexes and formation of Golgi $\mathrm{Ca}^{2+}$ gradients in pancreatic acinar cells. J Biol Chem 280: 1579415799.

Eilers M, Endo T, Schatz G. 1989. Adriamycin, a drug interacting with acidic phospholipids, blocks import of precursor proteins by isolated yeast mitochondria. J Biol Chem 264: 2945-2950.

Elbaz Y, Schuldiner M. 2011. Staying in touch: The molecular era of organelle contact sites. Trends Biochem Sci 36: 616-623.

Emoto K, Kuge O, Nishijima M, Umeda M. 1999. Isolation of a Chinese hamster ovary cell mutant defective in intramitochondrial transport of phosphatidylserine. Proc Natl Acad Sci 96: 12400-12405.

Frederick RL, McCaffery JM, Cunningham KW, Okamoto K, Shaw JM. 2004. Yeast Miro GTPase, Gemlp, regulates mitochondrial morphology via a novel pathway. J Cell Biol 167: 87-98.
Lipid Transport between the ER and Mitochondria

Frederick RL, Okamoto K, Shaw JM. 2008. Multiple pathways influence mitochondrial inheritance in budding yeast. Genetics 178: 825-837.

Friedman JR, Webster BM, Mastronarde DN, Verhey KJ, Voeltz GK. 2010. ER sliding dynamics and ER-mitochondrial contacts occur on acetylated microtubules. J Cell Biol 190: 363-375.

Friedman JR, Lackner LL, West M, DiBenedetto JR, Nunnari J, Voeltz GK. 2011. ER tubules mark sites of mitochondrial division. Science 334: 358-362.

Futerman AH. 2006. Intracellular trafficking of sphingolipids: Relationship to biosynthesis. Biochim Biophys Acta 1758: 1885-1892.

Gaigg B, Simbeni R, Hrastnik C, Paltauf F, Daum G. 1994. Characterization of a microsomal subfraction associated with mitochondria of the yeast, Saccharomyces cerevisiae. Involvement in synthesis and import of phospholipids into mitochondria. Biochim Biophys Acta 1234: 214-220.

Gardocki ME, Jani N, Lopes JM. 2005. Phosphatidylinosito biosynthesis: Biochemistry and regulation. Biochim Biophys Acta 1735: 89-100.

Gebert N, Joshi AS, Kutik S, Becker T, McKenzie M, Guan XL, Mooga VP, Stroud DA, Kulkarni G, Wenk MR, et al. 2009. Mitochondrial cardiolipin involved in outer-membrane protein biogenesis: Implications for Barth syndrome. Curr Biol 19: 2133-2139.

Gibellini F, Smith TK. 2010. The Kennedy pathway-De novo synthesis of phosphatidylethanolamine and phosphatidylcholine. IUBMB Life 62: 414-428.

Gibellini F, Hunter WN, Smith TK. 2009. The ethanolamine branch of the Kennedy pathway is essential in the bloodstream form of Trypanosoma brucei. Mol Microbiol 73: $826-843$.

Gohil VM, Greenberg ML. 2009. Mitochondrial membrane biogenesis: Phospholipids and proteins go hand in hand. J Cell Biol 184: 469-472.

Gohil VM, Thompson MN, Greenberg ML. 2005. Synthetic lethal interaction of the mitochondrial phosphatidylethanolamine and cardiolipin biosynthetic pathways in Saccharomyces cerevisiae. J Biol Chem 280: 35410-35416.

Gulshan K, Schmidt JA, Shahi P, Moye-Rowley WS. 2008. Evidence for the bifunctional nature of mitochondrial phosphatidylserine decarboxylase: Role in Pdr3-dependent retrograde regulation of PDR5 expression. $\mathrm{Mol}$ Cell Biol 28: 5851-5864.

Harner M, Körner C, Walther D, Mokranjac D, Kaesmacher J, Welsch U, Griffith J, Mann M, Reggiori F, Neupert W. 2011. The mitochondrial contact site complex, a determinant of mitochondrial architecture. EMBO J 30: $4356-$ 4370.

Harris TE, Finck BN. 2011. Dual function lipin proteins and glycerolipid metabolism. Trends Endocrinol Metab 22: 226-233.

Hauet T, Liu J, Li H, Gazouli M, Culty M, Papadopoulos V. 2002. PBR, StAR, and PKA: Partners in cholesterol transport in steroidogenic cells. Endocr Res 28: 395-401.

Hauet T, Yao Z-X, Bose HS, Wall CT, Han Z, Li W, Hales DB, Miller WL, Culty M, Papadopoulos V. 2005. Peripheral-type benzodiazepine receptor-mediated action of steroidogenic acute regulatory protein on cholesterol 
V.V. Flis and G. Daum

entry into leydig cell mitochondria. Mol Endocrinol 19: $540-554$.

Heikinheimo L, Somerharju P. 1998. Preferential decarboxylation of hydrophilic phosphatidylserine species in cultured cells. Implications on the mechanism of transport to mitochondria and cellular aminophospholipid species compositions. J Biol Chem 273: 3327-3335.

Henneberry AL, McMaster CR. 1999. Cloning and expression of a human choline/ethanolaminephosphotransferase: Synthesis of phosphatidylcholine and phosphatidylethanolamine. Biochem J 339(Pt 2): 291-298.

Hermansson M, Hokynar K, Somerharju P. 2011. Mechanisms of glycerophospholipid homeostasis in mammalian cells. Prog Lipid Res 50: 240-257.

Hishikawa D, Shindou H, Kobayashi S, Nakanishi $H$, Taguchi R, Shimizu T. 2008. Discovery of a lysophospholipid acyltransferase family essential for membrane asymmetry and diversity. Proc Natl Acad Sci 105: 2830-2835.

Holthuis JCM, Levine TP. 2005. Lipid traffic: Floppy drives and a superhighway. Nat Rev Mol Cell Biol 6: 209-220.

Hong JH, Chung G, Cowan AK. 2009. Delayed leaf senescence by exogenous lyso-phosphatidylethanolamine: Towards a mechanism of action. Plant Physiol Biochem 47: 526-534.

Hoppins S, Collins SR, Cassidy-Stone A, Hummel E, Devay RM, Lackner LL, Westermann B, Schuldiner M, Weissman JS, Nunnari J. 2011. A mitochondrial-focused genetic interaction map reveals a scaffold-like complex required for inner membrane organization in mitochondria. J Cell Biol 195: 323-340.

Horvath SE, Böttinger L, Vögtle F-N, Wiedeman N, Meisinger C, Becker T, Daum G. 2012. Processing and topology of the yeast mitochondrial phosphatidylserine decarboxylase 1. J Biol Chem 287: 36744-36755.

Houtkooper RH, Akbari H, van Lenthe H, Kulik W, Wanders RJA, Frentzen M, Vaz FM. 2006. Identification and characterization of human cardiolipin synthase. FEBS Lett 580: 3059-3064.

Hovius R, Faber B, Brigot B, Nicolay K, de Kruijff B. 1992. On the mechanism of the mitochondrial decarboxylation of phosphatidylserine. J Biol Chem 267: 16790-16795.

Ikonen E. 2008. Cellular cholesterol trafficking and compartmentalization. Nat Rev Mol Cell Biol 9: 125-138.

Jacquier N, Schneiter R. 2012. Mechanisms of sterol uptake and transport in yeast. J Steroid Biochem Mol Biol 129: $70-78$.

Janssen MJ, Koorengevel MC, de Kruijff B, de Kroon AI. 1999. Transbilayer movement of phosphatidylcholine in the mitochondrial outer membrane of Saccharomyces cerevisiae is rapid and bidirectional. Biochim Biophys Acta 1421: $64-76$.

Jiang F, Rizavi HS, Greenberg ML. 1997. Cardiolipin is not essential for the growth of Saccharomyces cerevisiae on fermentable or non-fermentable carbon sources. Mol Microbiol 26: 481-491.

Jiang F, Ryan MT, Schlame M, Zhao M, Gu Z, Klingenberg M, Pfanner N, Greenberg ML. 2000. Absence of cardiolipin in the crd1 null mutant results in decreased mitochondrial membrane potential and reduced mitochondrial function. J Biol Chem 275: 22387-22394.
Joshi AS, Zhou J, Gohil VM, Chen S, Greenberg ML. 2009. Cellular functions of cardiolipin in yeast. Biochim Biophys Acta 1793: 212-218.

Joshi AS, Thompson MN, Fei N, Hüttemann M, Greenberg ML. 2012. Cardiolipin and mitochondrial phosphatidylethanolamine have overlapping functions in mitochondrial fusion in Saccharomyces cerevisiae. J Biol Chem 287: 17589-17597.

Kanfer J, Kennedy EP. 1964. Metabolism and function of bacterial lipids. II. Biosynthesis of phospholipids in escherichia coli. J Biol Chem 239: 1720-1726.

Katayama K, Sakurai I, Wada H. 2004. Identification of an Arabidopsis thaliana gene for cardiolipin synthase located in mitochondria. FEBS Lett 577: 193-198.

Kelley MJ, Carman GM. 1987. Purification and characterization of CDP-diacylglycerol synthase from Saccharomyces cerevisiae. J Biol Chem 262: 14563-14570.

Kennedy EP. 1956. The synthesis of cytidine diphosphate choline, cytidine diphosphate ethanolamine, and related compounds. J Biol Chem 222: 185-191.

Kennedy EP, Weiss SB. 1956. The function of cytidine coenzymes in the biosynthesis of phospholipides. J Biol Chem 222: $193-214$

Kevala JH, Kim HY. 2001. Determination of substrate preference in phosphatidylserine decarboxylation by liquid chromatography-electrospray ionization mass spectrometry. Anal Biochem 292: 130-138.

King SR, Stocco DM. 1996. ATP and a mitochondrial electrochemical gradient are required for functional activity of the steroidogenic acute regulatory (StAR) protein in isolated mitochondria. Endocr Res 22: 505-514.

Kitagaki H, Cowart LA, Matmati N, Vaena de Avalos S, Novgorodov SA, Zeidan YH, Bielawski J, Obeid LM, Hannun YA. 2007. Isc1 regulates sphingolipid metabolism in yeast mitochondria. Biochim Biophys Acta 1768: 2849-2861.

Kitagaki H, Cowart LA, Matmati N, Montefusco D, Gandy J, de Avalos SV, Novgorodov SA, Zheng J, Obeid LM, Hannun YA. 2009. ISC1-dependent metabolic adaptation reveals an indispensable role for mitochondria in induction of nuclear genes during the diauxic shift in Saccharomyces cerevisiae. J Biol Chem 284: 10818-10830.

Kodaki T, Yamashita S. 1987. Yeast phosphatidylethanolamine methylation pathway. Cloning and characterization of two distinct methyltransferase genes. J Biol Chem 262: $15428-15435$.

Kohlwein SD, Daum G, Schneiter R, Paltauf F. 1996. Phospholipids: Synthesis, sorting, subcellular traffic-the yeast approach. Trends Cell Biol 6: 260-266.

Kornmann B, Currie E, Collins SR, Schuldiner M, Nunnari J, Weissman JS, Walter P. 2009. An ER-mitochondria tethering complex revealed by a synthetic biology screen. Science 325: 477-481.

Kornmann B, Osman C, Walter P. 2011. The conserved GTPase Gem1 regulates endoplasmic reticulum-mitochondria connections. Proc Natl Acad Sci 108: 1415114156.

Kozlov MM, McMahon HT, Chernomordik LV. 2010. Protein-driven membrane stresses in fusion and fission. Trends Biochem Sci 35: 699-706. 
Lipid Transport between the ER and Mitochondria

Krueger KE, Papadopoulos V. 1990. Peripheral-type benzodiazepine receptors mediate translocation of cholesterol from outer to inner mitochondrial membranes in adrenocortical cells. J Biol Chem 265: 15015-15022.

Kuchler K, Daum G, Paltauf F. 1986. Subcellular and submitochondrial localization of phospholipid-synthesizing enzymes in Saccharomyces cerevisiae. J Bacteriol 165: 901-910.

Kuge O, Yamakawa Y, Nishijima M. 2001. Enhancement of transport-dependent decarboxylation of phosphatidylserine by S100B protein in permeabilized Chinese hamster ovary cells. J Biol Chem 276: 23700-23706.

Lampl M, Leber A, Paltauf F, Daum G. 1994. Import of phosphatidylinositol and phosphatidylcholine into mitochondria of the yeast, Saccharomyces cerevisiae. FEBS Lett 356: 1-4.

Lands WE. 1958. Metabolism of glycerolipides; a comparison of lecithin and triglyceride synthesis. J Biol Chem 231: 883-888.

Lavieu G, Orci L, Shi L, Geiling M, Ravazzola M, Wieland F, Cosson P, Rothman JE. 2010. Induction of cortical endoplasmic reticulum by dimerization of a coatomerbinding peptide anchored to endoplasmic reticulum membranes. Proc Natl Acad Sci 107: 6876-6881.

Leber R, Zinser E, Zellnig G, Paltauf F, Daum G. 1994. Characterization of lipid particles of the yeast, Saccharomyces cerevisiae. Yeast 10: 1421-1428.

Lebiedzinska M, Szabadkai G, Jones AWE, Duszynski J, Wieckowski MR. 2009. Interactions between the endoplasmic reticulum, mitochondria, plasma membrane and other subcellular organelles. Int J Biochem Cell Biol 41: 1805-1816.

Letts VA, Klig LS, Bae-Lee M, Carman GM, Henry SA. 1983. Isolation of the yeast structural gene for the membraneassociated enzyme phosphatidylserine synthase. Proc Natl Acad Sci 80: 7279-7283.

Levine T, Loewen C. 2006. Inter-organelle membrane contact sites: Through a glass, darkly. Curr Opin Cell Biol 18: 371-378.

Levy M, Futerman AH. 2010. Mammalian ceramide synthases. IUBMB Life 62: 347-356.

Li Z, Agellon LB, Vance DE. 2005. Phosphatidylcholine homeostasis and liver failure. J Biol Chem 280: 3779837802.

Liapis A, Chen FW, Davies JP, Wang R, Ioannou YA. 2012. MLN64 transport to the late endosome is regulated by binding to 14-3-3 via a non-canonical binding site. PLoS ONE 7: e34424.

Lim P, Cornell R, Vance DE. 1986. The supply of both CDPcholine and diacylglycerol can regulate the rate of phosphatidylcholine synthesis in HeLa cells. Biochem Cell Biol 64: 692-698.

Lu B, Xu FY, Jiang YJ, Choy PC, Hatch GM, Grunfeld C, Feingold KR. 2006. Cloning and characterization of a cDNA encoding human cardiolipin synthase (hCLS1). J Lipid Res 47: 1140-1145.

Malhotra A, Xu Y, Ren M, Schlame M. 2009. Formation of molecular species of mitochondrial cardiolipin. 1. A novel transacylation mechanism to shuttle fatty acids between sn-1 and sn-2 positions of multiple phospholipid species. Biochim Biophys Acta 1791: 314-320.
Manoharan K, Chae HS, Cha JM, Cho SH, Shin SH, Cho BH, Lee WS. 2000. Synthesis of phosphatidylserine in carrot cells cultured under carbon-source starvation. Plant Cell Physiol 41: 1143-1148.

Mao C, Wadleigh M, Jenkins GM, Hannun YA, Obeid LM. 1997. Identification and characterization of Saccharomyces cerevisiae dihydrosphingosine-1-phosphate phosphatase. J Biol Chem 272: 28690-28694.

Matsumoto K, Kusaka J, Nishibori A, Hara H. 2006. Lipid domains in bacterial membranes. Mol Microbiol 61: $1110-1117$.

Maxfield FR, Wüstner D. 2002. Intracellular cholesterol transport. J Clin Invest 110: 891-898.

McEnery MW, Snowman AM, Trifiletti RR, Snyder SH. 1992. Isolation of the mitochondrial benzodiazepine receptor: Association with the voltage-dependent anion channel and the adenine nucleotide carrier. Proc Natl Acad Sci 89: 3170-3174.

Mencarelli C, Losen M, Hammels C, De Vry J, Hesselink MKC, Steinbusch HWM, De Baets MH, MartínezMartínez P. 2010. The ceramide transporter and the Goodpasture antigen binding protein: One proteinone function? J Neurochem 113: 1369-1386.

Michel AH, Kornmann B. 2012. The ERMES complex and ER-mitochondria connections. Biochem Soc Trans 40: $445-450$.

Midzak A, Rone M, Aghazadeh Y, Culty M, Papadopoulos V. 2011. Mitochondrial protein import and the genesis of steroidogenic mitochondria. Mol Cell Endocrinol 336: $70-79$.

Mileykovskaya E, Zhang M, Dowhan W. 2005. Cardiolipin in energy transducing membranes. Biochemistry Mosc 70: $154-158$.

Miller WL, Auchus RJ. 2011. The molecular biology, biochemistry, and physiology of human steroidogenesis and its disorders. Endocr Rev 32: 81-151.

Miller WL, Bose HS. 2011. Early steps in steroidogenesis: Intracellular cholesterol trafficking. J Lipid Res 52: 21112135.

Minskoff SA, Greenberg ML. 1997. Phosphatidylglycerophosphate synthase from yeast. Biochim Biophys Acta 1348: $187-191$.

Misko A, Jiang S, Wegorzewska I, Milbrandt J, Baloh RH. 2010. Mitofusin 2 is necessary for transport of axonal mitochondria and interacts with the Miro/Milton complex. J Neurosci 30: 4232-4240.

Mukhin AG, Papadopoulos V, Costa E, Krueger KE. 1989. Mitochondrial benzodiazepine receptors regulate steroid biosynthesis. Proc Natl Acad Sci 86: 9813-9816.

Mullen TD, Hannun YA, Obeid LM. 2012. Ceramide synthases at the centre of sphingolipid metabolism and biology. Biochem J 441: 789-802.

Nebauer R, Schuiki I, Kulterer B, Trajanoski Z, Daum G. 2007. The phosphatidylethanolamine level of yeast mitochondria is affected by the mitochondrial components Oxalp and Ymelp. FEBS J 274: 6180-6190.

Nerlich A, von Orlow M, Rontein D, Hanson AD, Dörmann P. 2007. Deficiency in phosphatidylserine decarboxylase activity in the psd 1 psd2 psd 3 triple mutant of Arabidopsis affects phosphatidylethanolamine accumulation in mitochondria. Plant Physiol 144: 904-914. 
V.V. Flis and G. Daum

Nguyen TT, Lewandowska A, Choi J-Y, Markgraf DF, Junker M, Bilgin M, Ejsing CS, Voelker DR, Rapoport TA, Shaw JM. 2012. Gem1 and ERMES do not directly affect phosphatidylserine transport from ER to mitochondria or mitochondrial inheritance. Traffic 13: 880-890.

Nikawa JI, Yamashita S. 1981. Characterization of phosphatidylserine synthase from Saccharomyces cerevisiae and a mutant defective in the enzyme. Biochim Biophys Acta 665: 420-426.

Nikawa J, Kodaki T, Yamashita S. 1987. Primary structure and disruption of the phosphatidylinositol synthase gene of Saccharomyces cerevisiae. J Biol Chem 262: 4876-4881.

Novgorodov SA, Gudz TI. 2009. Ceramide and mitochondria in ischemia/reperfusion. J Cardiovasc Pharmacol 53: 198-208.

Novgorodov SA, Wu BX, Gudz TI, Bielawski J, Ovchinnikova TV, Hannun YA, Obeid LM. 2011. Novel pathway of ceramide production in mitochondria: Thioesterase and neutral ceramidase produce ceramide from sphingosine and acyl-CoA. J Biol Chem 286: 25352-25362.

Nowicki M, Müller F, Frentzen M. 2005. Cardiolipin synthase of Arabidopsis thaliana. FEBS Lett 579: 2161-2165.

Osman C, Haag M, Potting C, Rodenfels J, Dip PV, Wieland FT, Brügger B, Westermann B, Langer T. 2009a. The genetic interactome of prohibitins: Coordinated control of cardiolipin and phosphatidylethanolamine by conserved regulators in mitochondria. J Cell Biol 184: 583-596.

Osman C, Merkwirth C, Langer T. 2009b. Prohibitins and the functional compartmentalization of mitochondrial membranes. J Cell Sci 122: 3823-3830.

Osman C, Haag M, Wieland FT, Brügger B, Langer T. 2010. A mitochondrial phosphatase required for cardiolipin biosynthesis: The PGP phosphatase Gep4. EMBO J 29: 1976-1987.

Osman C, Voelker DR, Langer T. 2011. Making heads or tails of phospholipids in mitochondria. J Cell Biol 192: 7-16.

Ouni I, Flick K, Kaiser P. 2010. A transcriptional activator is part of an SCF ubiquitin ligase to control degradation of its cofactors. Mol Cell 40: 954-964.

Padilla-López S, Langager D, Chan C-H, Pearce DA. 2012. BTN1, the Saccharomyces cerevisiae homolog to the human Batten disease gene, is involved in phospholipid distribution. Dis Model Mech 5: 191-199.

Perry RJ, Ridgway ND. 2005. Molecular mechanisms and regulation of ceramide transport. Biochim Biophys Acta 1734: $220-234$.

Petrescu AD, Gallegos AM, Okamura Y, Strauss JF 3rd, Schroeder F. 2001. Steroidogenic acute regulatory protein binds cholesterol and modulates mitochondrial membrane sterol domain dynamics. J Biol Chem 276: 3697036982.

Potting C, Wilmes C, Engmann T, Osman C, Langer T. 2010. Regulation of mitochondrial phospholipids by Ups1/ PRELI-like proteins depends on proteolysis and Mdm35. EMBO J 29: 2888-2898.

Rabl R, Soubannier V, Scholz R, Vogel F, Mendl N, VasiljevNeumeyer A, Körner C, Jagasia R, Keil T, Baumeister W, et al. 2009. Formation of cristae and crista junctions in mitochondria depends on antagonism between Fcj1 and Su e/g. J Cell Biol 185: 1047-1063.
Ridgway ND, Yao Z, Vance DE. 1989. Phosphatidylethanolamine levels and regulation of phosphatidylethanolamine N-methyltransferase. J Biol Chem 264: $1203-$ 1207.

Riekhof WR, Voelker DR. 2006. Uptake and utilization of lyso-phosphatidylethanolamine by Saccharomyces cerevisiae. J Biol Chem 281: 36588-36596.

Riekhof WR, Wu J, Gijón MA, Zarini S, Murphy RC, Voelker DR. 2007a. Lysophosphatidylcholine metabolism in Saccharomyces cerevisiae: The role of P-type ATPases in transport and a broad specificity acyltransferase in acylation. J Biol Chem 282: 36853-36861.

Riekhof WR, Wu J, Jones JL, Voelker DR. 2007b. Identification and characterization of the major lysophosphatidylethanolamine acyltransferase in Saccharomyces cerevisiae. J Biol Chem 282: 28344-28352.

Rone MB, Fan J, Papadopoulos V. 2009. Cholesterol transport in steroid biosynthesis: Role of protein-protein interactions and implications in disease states. Biochim Biophys Acta 1791: 646-658.

Rontein D, Wu W-I, Voelker DR, Hanson AD. 2003. Mitochondrial phosphatidylserine decarboxylase from higher plants. Functional complementation in yeast, localization in plants, and overexpression in Arabidopsis. Plant Physiol 132: 1678-1687.

Saba JD, Nara F, Bielawska A, Garrett S, Hannun YA. 1997. The BST1 gene of Saccharomyces cerevisiae is the sphingosine-1-phosphate lyase. J Biol Chem 272: 2608726090.

Salama NR, Schekman RW. 1995. The role of coat proteins in the biosynthesis of secretory proteins. Curr Opin Cell Biol 7: 536-543.

Schlame M. 2008. Cardiolipin synthesis for the assembly of bacterial and mitochondrial membranes. J Lipid Res 49: 1607-1620.

Schlame M, Ren M. 2009. The role of cardiolipin in the structural organization of mitochondrial membranes. Biochim Biophys Acta 1788: 2080-2083.

Schlame M, Brody S, Hostetler KY. 1993. Mitochondrial cardiolipin in diverse eukaryotes. Comparison of biosynthetic reactions and molecular acyl species. Eur J Biochem 212: $727-735$.

Schulz TA, Prinz WA. 2007. Sterol transport in yeast and the oxysterol binding protein homologue (OSH) family. Biochim Biophys Acta 1771: 769-780.

Schumacher MM, Choi J-Y, Voelker DR. 2002. Phosphatidylserine transport to the mitochondria is regulated by ubiquitination. J Biol Chem 277: 51033-51042.

Serricchio M, Bütikofer P. 2011. Trypanosoma brucei: A model microorganism to study eukaryotic phospholipid biosynthesis. FEBS J 278: 1035-1046.

Shiao YJ, Lupo G, Vance JE. 1995. Evidence that phosphatidylserine is imported into mitochondria via a mitochondria-associated membrane and that the majority of mitochondrial phosphatidylethanolamine is derived from decarboxylation of phosphatidylserine. J Biol Chem 270: 11190-11198.

Shiao YJ, Balcerzak B, Vance JE. 1998. A mitochondrial membrane protein is required for translocation of phosphatidylserine from mitochondria-associated membranes to mitochondria. Biochem J 331: 217-223. 
Lipid Transport between the ER and Mitochondria

Shindou H, Hishikawa D, Harayama T, Yuki K, Shimizu T. 2009. Recent progress on acyl CoA: Lysophospholipid acyltransferase research. J Lipid Res 50 (Suppl): S46-S51.

Simbeni R, Paltauf F, Daum G. 1990. Intramitochondrial transfer of phospholipids in the yeast, Saccharomyces cerevisiae. J Biol Chem 265: 281-285.

Siskind LJ, Colombini M. 2000. The lipids C2- and C16ceramide form large stable channels. Implications for apoptosis. J Biol Chem 275: 38640-38644.

Soccio RE, Breslow JL. 2004. Intracellular cholesterol transport. Arterioscler Thromb Vasc Biol 24: 1150-1160.

Sorger D, Daum G. 2003. Triacylglycerol biosynthesis in yeast. Appl Microbiol Biotechnol 61: 289-299.

Sperka-Gottlieb CD, Hermetter A, Paltauf F, Daum G. 1988. Lipid topology and physical properties of the outer mitochondrial membrane of the yeast, Saccharomyces cerevisiae. Biochim Biophys Acta 946: 227-234.

Stiban J, Tidhar R, Futerman AH. 2010. Ceramide synthases: Roles in cell physiology and signaling. Adv Exp Med Biol 688: $60-71$.

Stocco DM. 2000. Intramitochondrial cholesterol transfer. Biochim Biophys Acta 1486: 184-197.

Strauss JF 3rd, Kallen CB, Christenson LK, Watari H, Devoto L, Arakane F, Kiriakidou M, Sugawara T. 1999. The steroidogenic acute regulatory protein (StAR): A window into the complexities of intracellular cholesterol trafficking. Recent Prog Horm Res 54: 394-395.

Stroud DA, Oeljeklaus S, Wiese S, Bohnert M, Lewandrowski U, Sickmann A, Guiard B, van der Laan M, Warscheid B, Wiedemann N. 2011. Composition and topology of the endoplasmic reticulum-mitochondria encounter structure. J Mol Biol 413: 743-750.

Sundler R, Akesson B. 1975. Regulation of phospholipid biosynthesis in isolated rat hepatocytes. Effect of different substrates. J Biol Chem 250: 3359-3367.

Suzuki M, Muranaka T. 2007. Molecular genetics of plant sterol backbone synthesis. Lipids 42: 47-54.

Tamura Y, Endo T, Iijima M, Sesaki H. 2009. Ups1p and Ups2p antagonistically regulate cardiolipin metabolism in mitochondria. J Cell Biol 185: 1029-1045.

Tamura Y, Onguka O, Hobbs AEA, Jensen RE, Iijima M, Claypool SM, Sesaki H. 2012. Role for two conserved intermembrane space proteins, Ups1p and Up2p, in intra-mitochondrial phospholipid trafficking. J Biol Chem 287: $15205-15218$.

Trotter PJ, Voelker DR. 1995. Identification of a non-mitochondrial phosphatidylserine decarboxylase activity (PSD2) in the yeast Saccharomyces cerevisiae. J Biol Chem 270: 6062-6070.

Trotter PJ, Pedretti J, Voelker DR. 1993. Phosphatidylserine decarboxylase from Saccharomyces cerevisiae. Isolation of mutants, cloning of the gene, and creation of a null allele. J Biol Chem 268: 21416-21424.

Trotter PJ, Pedretti J, Yates R, Voelker DR. 1995. Phosphatidylserine decarboxylase 2 of Saccharomyces cerevisiáe. Cloning and mapping of the gene, heterologous expression, and creation of the null allele. J Biol Chem 270: 6071-6080.

Trotter PJ, Wu WI, Pedretti J, Yates R, Voelker DR. 1998. A genetic screen for aminophospholipid transport mutants identifies the phosphatidylinositol 4-kinase, STT4p, as an essential component in phosphatidylserine metabolism. J Biol Chem 273: 13189-13196.

Tuller G, Daum G. 1995. Import of sterols into mitochondria of the yeast Saccharomyces cerevisiae. FEBS Lett 372: 29-32.

Tuller G, Hrastnik C, Achleitner G, Schiefthaler U, Klein F, Daum G. 1998. YDL142c encodes cardiolipin synthase (Cls1p) and is non-essential for aerobic growth of Saccharomyces cerevisiae. FEBS Lett 421: 15-18.

Vance JE. 1990. Phospholipid synthesis in a membrane fraction associated with mitochondria. J Biol Chem 265: $7248-7256$.

Vance JE. 2008. Phosphatidylserine and phosphatidylethanolamine in mammalian cells: Two metabolically related aminophospholipids. J Lipid Res 49: 1377-1387.

van den Brink-van der Laan E, Killian JA, de Kruijff B. 2004. Nonbilayer lipids affect peripheral and integral membrane proteins via changes in the lateral pressure profile. Biochim Biophys Acta 1666: 275-288.

van den Hazel HB, Pichler H, do Valle Matta MA, Leitner E, Goffeau A, Daum G. 1999. PDR16 and PDR17, two homologous genes of Saccharomyces cerevisiae, affect lipid biosynthesis and resistance to multiple drugs. J Biol Chem 274: 1934-1941.

van der Laan M, Bohnert M, Wiedemann N, Pfanner N. 2012. Role of MINOS in mitochondrial membrane architecture and biogenesis. Trends Cell Biol 22: 185-192.

van der Veen JN, Lingrell S, Vance DE. 2012. The membrane lipid, phosphatidylcholine, is an unexpected source of triacylglycerol in the liver. J Biol Chem 287: 2341823426.

van Meer G, Hoetzl S. 2010. Sphingolipid topology and the dynamic organization and function of membrane proteins. FEBS Lett 584: 1800-1805.

van Meer G, Voelker DR, Feigenson GW. 2008. Membrane lipids: Where they are and how they behave. Nat Rev Mol Cell Biol 9: 112-124.

Vial HJ, Thuet MJ, Philippot JR. 1982. Phospholipid biosynthesis in synchronous Plasmodium falciparum cultures. J Protozool 29: 258-263.

Voelker DR. 1984. Phosphatidylserine functions as the major precursor of phosphatidylethanolamine in cultured BHK-21 cells. Proc Natl Acad Sci 81: 2669-2673.

Voelker DR. 1985. Disruption of phosphatidylserine translocation to the mitochondria in baby hamster kidney cells. J Biol Chem 260: 14671-14676.

Voelker DR. 1988. Phosphatidylserine translocation in animal cells. Prog Clin Biol Res 282: 153-164.

Voelker DR. 1989a. Phosphatidylserine translocation to the mitochondrion is an ATP-dependent process in permeabilized animal cells. Proc Natl Acad Sci 86: 9921-9925.

Voelker DR. 1989b. Reconstitution of phosphatidylserine import into rat liver mitochondria. J Biol Chem 264: 8019-8025.

Voelker DR. 1990. Characterization of phosphatidylserine synthesis and translocation in permeabilized animal cells. J Biol Chem 265: 14340-14346.

Voelker DR. 1991. Adriamycin disrupts phosphatidylserine import into the mitochondria of permeabilized $\mathrm{CHO}-\mathrm{K} 1$ cells. J Biol Chem 266: 12185-12188. 
V.V. Flis and G. Daum

Voelker DR. 1992. Phosphatidylserine synthesis and transport to mitochondria in permeabilized animal cells. Methods Enzymol 209: 530-534.

Voelker DR. 1993. The ATP-dependent translocation of phosphatidylserine to the mitochondria is a process that is restricted to the autologous organelle. J Biol Chem 268: 7069-7074.

Voelker DR. 2005. Bridging gaps in phospholipid transport. Trends Biochem Sci 30: 396-404.

Voelker DR. 2009. Genetic and biochemical analysis of nonvesicular lipid traffic. Annu Rev Biochem 78: 827-856.

Voelker DR, Frazier JL. 1986. Isolation and characterization of a Chinese hamster ovary cell line requiring ethanolamine or phosphatidylserine for growth and exhibiting defective phosphatidylserine synthase activity. J Bio Chem 261: 1002-1008.

von der Malsburg K, Müller JM, Bohnert M, Oeljeklaus S, Kwiatkowska P, Becker T, Loniewska-Lwowska A, Wiese S, Rao S, Milenkovic D, et al. 2011. Dual role of mitofilin in mitochondrial membrane organization and protein biogenesis. Dev Cell 21: 694-707.

Wagner A, Daum G. 2005. Formation and mobilization of neutral lipids in the yeast Saccharomyces cerevisiae. Biochem Soc Trans 33: 1174-1177.

Wriessnegger $\mathrm{T}$, Leitner $\mathrm{E}$, Belegratis $\mathrm{MR}$, Ingolic $\mathrm{E}$, Daum G. 2009. Lipid analysis of mitochondrial membranes from the yeast Pichia pastoris. Biochim Biophys Acta 1791: 166-172.

Wu WI, Voelker DR. 2001. Characterization of phosphatidylserine transport to the locus of phosphatidylserine decarboxylase 2 in permeabilized yeast. J Biol Chem 276: 7114-7121.

Wu W-I, Voelker DR. 2004. Reconstitution of phosphatidylserine transport from chemically defined donor membranes to phosphatidylserine decarboxylase 2 implicates specific lipid domains in the process. J Biol Chem 279: 6635-6642.

Wu WI, Routt S, Bankaitis VA, Voelker DR. 2000. A new gene involved in the transport-dependent metabolism of phosphatidylserine, PSTB2/PDR17, shares sequence similarity with the gene encoding the phosphatidylinositol/phosphatidylcholine transfer protein, SEC14. J Biol Chem 275: 14446-14456.

Xu Y, Malhotra A, Ren M, Schlame M. 2006. The enzymatic function of tafazzin. J Biol Chem 281: 39217-39224.

Yan J, Xiong Y. 2010. Targeted ubiquitylation: The prey becomes predator. Mol Cell 40: 853-855.

Zhang M, Liu P, Dwyer NK, Christenson LK, Fujimoto T, Martinez F, Comly M, Hanover JA, Blanchette-Mackie EJ, Strauss JF 3rd. 2002. MLN64 mediates mobilization of lysosomal cholesterol to steroidogenic mitochondria. J Biol Chem 277: 33300-33310.

Zinser E, Daum G. 1995. Isolation and biochemical characterization of organelles from the yeast, Saccharomyces cerevisiae. Yeast 11: 493-536.

Zinser E, Sperka-Gottlieb CD, Fasch EV, Kohlwein SD, Paltauf F, Daum G. 1991. Phospholipid synthesis and lipid composition of subcellular membranes in the unicellular eukaryote Saccharomyces cerevisiae. J Bacteriol 173: 2026-2034. 


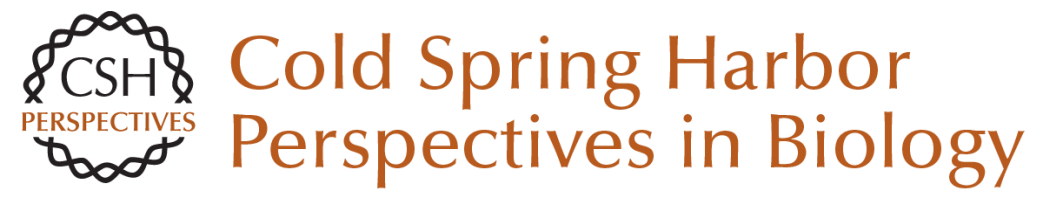

\section{Lipid Transport between the Endoplasmic Reticulum and Mitochondria}

Vid V. Flis and Günther Daum

Cold Spring Harb Perspect Biol 2013; doi: 10.1101/cshperspect.a013235

Subject Collection The Endoplasmic Reticulum

Sorting and Export of Proteins at the Endoplasmic Reticulum

Ishier Raote, Sonashree Saxena and Vivek Malhotra

Endoplasmic Reticulum Membrane Contact Sites, Lipid Transport, and Neurodegeneration Andrés Guillén-Samander and Pietro De Camilli

AMPylation and Endoplasmic Reticulum Protein Folding Homeostasis

Luke A. Perera and David Ron

The Endoplasmic Reticulum and the Fidelity of Nascent Protein Localization

Michael J. McKenna and Sichen Shao

Endoplasmic Reticulum Architecture and Inter-Organelle Communication in Metabolic Health and Disease

Ana Paula Arruda and Günes Parlakgül

Regulation and Functions of the ER-Associated

Nrf1 Transcription Factor

Gary Ruvkun and Nicolas Lehrbach

Mechanism of Protein Translocation by the Sec61

Translocon Complex

Samuel Itskanov and Eunyong Park

Evolutionary Aspects of the Unfolded Protein

Response

Kazutoshi Mori
Glycerolipid Synthesis and Lipid Droplet

Formation in the Endoplasmic Reticulum

Robert V. Farese, Jr. and Tobias C. Walther

The Biogenesis of Multipass Membrane Proteins Luka Smalinskaite and Ramanujan S. Hegde

A TAle of Two Pathways: Tail-Anchored Protein Insertion at the Endoplasmic Reticulum Alina Guna, Masami Hazu, Giovani Pinton Tomaleri, et al.

Cholesterol Transport to the Endoplasmic

Reticulum John P. Kennelly and Peter Tontonoz

The Role of the Rhomboid Superfamily in ER

Protein Quality Control: From Mechanisms and

Functions to Diseases

Satarupa Bhaduri, Nicola A. Scott and Sonya E. Neal

ER-Phagy: Quality and Quantity Control of the

Endoplasmic Reticulum by Autophagy Haruka Chino and Noboru Mizushima

Structure and Function of the Nuclear Pore Complex

Stefan Petrovic, George W. Mobbs, Christopher J. Bley, et al.

Post-Translational Regulation of HMG CoA

Reductase

Youngah Jo and Russell A. DeBose-Boyd

For additional articles in this collection, see http://cshperspectives.cshlp.org/cgi/collection/

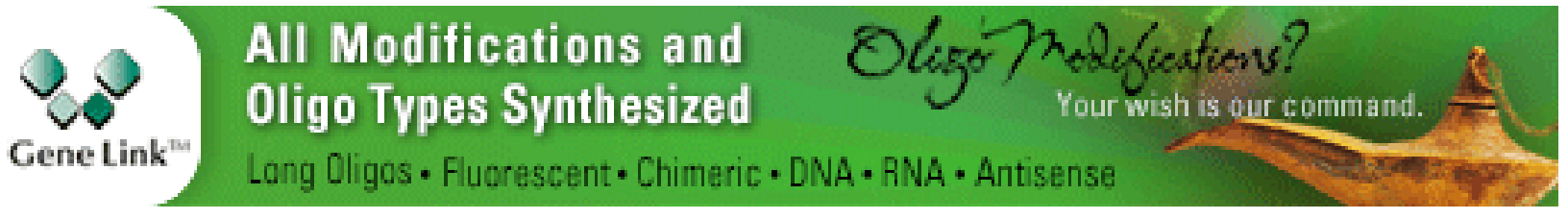


For additional articles in this collection, see http://cshperspectives.cshlp.org/cgi/collection/

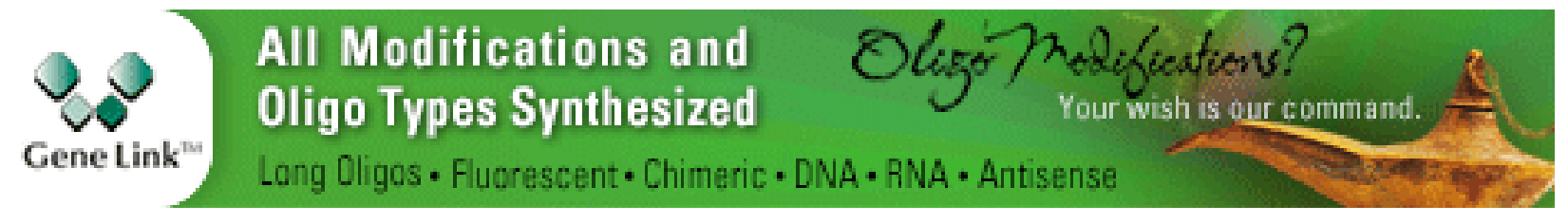

Copyright @ 2013 Cold Spring Harbor Laboratory Press; all rights reserved 